\title{
Design and Comprehensive Characterization of Tetramethylpyrazine (TMP) for Targeted Lung Delivery as Inhalation Aerosols in Pulmonary Hypertension (PH): In Vitro Human Lung Cell Culture and In Vivo Efficacy
}

\author{
Priya Muralidharan ${ }^{1}$, Maria F. Acosta ${ }^{1}$, Alexan I. Gomez ${ }^{1,2,3}$, Carissa Grijalva ${ }^{1}$, Haiyang Tang ${ }^{3}$ (D), \\ Jason X.-J. Yuan ${ }^{3,4}$ and Heidi M. Mansour 1,3,5,6,* \\ 1 College of Pharmacy, The University of Arizona, Tucson, AZ 85721, USA; \\ priyam@pharmacy.arizona.edu (P.M.); acosta@pharmacy.arizona.edu (M.F.A.); \\ alexan.gomez@medtronic.com (A.I.G.); cari10g@email.arizona.edu (C.G.) \\ 2 Department of Biomedical Engineering, The Arizona State University, Phoenix, AZ 85287, USA \\ 3 Department of Medicine, Division of Translational \& Regenerative Medicine, College of Medicine, The \\ University of Arizona, Tucson, AZ 85721, USA; haiyangtang@email.arizona.edu (H.T.); \\ jxyuan@health.ucsd.edu (J.X.-J.Y.) \\ 4 Department of Medicine, University of California, San Diego, La Jolla, CA 92093, USA \\ check for \\ updates \\ Citation: Muralidharan, P.; Acosta, \\ The BIO5 Research Institute, The University of Arizona, Tucson, AZ 85721, USA \\ Institute of the Environment, The University of Arizona, Tucson, AZ 85721, USA \\ *orrespondence: mansour@pharmacy.arizona.edu; Tel.: +1-520-626-2768
} M.F.; Gomez, A.I.; Grijalva, C.; Tang, H.; Yuan, J.X.-J.; Mansour, H.M. Design and Comprehensive Characterization of Tetramethylpyrazine (TMP) for Targeted Lung Delivery as Inhalation Aerosols in Pulmonary Hypertension (PH): In Vitro Human Lung Cell Culture and In Vivo Efficacy. Antioxidants 2021, 10, 427.

https://doi.org/10.3390/antiox10030427

Academic Editors: Trent E. Tipple and Peter Vitiello

Received: 7 February 2021

Accepted: 5 March 2021

Published: 11 March 2021

Publisher's Note: MDPI stays neutral with regard to jurisdictional claims in published maps and institutional affiliations.

Copyright: (C) 2021 by the authors Licensee MDPI, Basel, Switzerland. This article is an open access article distributed under the terms and conditions of the Creative Commons Attribution (CC BY) license (https:// creativecommons.org/licenses/by/ $4.0 /)$.

\begin{abstract}
This is the first study reporting on the design and development innovative inhaled formulations of the novel natural product antioxidant therapeutic, tetramethylpyrazine (TMP), also known as ligustrazine. TMP is obtained from Chinese herbs belonging to the class of Ligusticum. It is known to have antioxidant properties. It can act as a Nrf2/ARE activator and a Rho/ROCK inhibitor. The present study reports for the first time on the comprehensive characterization of raw TMP (non-spray dried) and spray dried TMP in a systematic manner using thermal analysis, electron microscopy, optical microscopy, and Raman spectroscopy. The in vitro aerosol dispersion performance of spray dried TMP was tested using three different FDA-approved unit-dose capsule-based human dry powder inhaler devices. In vitro human cellular studies were conducted on pulmonary cells from different regions of the human lung to examine the biocompatibility and non-cytotoxicity of TMP. Furthermore, the efficacy of inhaled TMP as both liquid and dry powder inhalation aerosols was tested in vivo using the monocrotaline (MCT)-induced $\mathrm{PH}$ rat model.
\end{abstract}

Keywords: respiratory drug delivery; ligustrazine; Rho/ROCK inhibitor; antioxidant; Nrf2; lung vascular disease; advanced spray drying; monocrotaline (MCT); rat model

\section{Introduction}

Pulmonary hypertension $(\mathrm{PH})$ is a serious life-threatening disease of the pulmonary and cardiovascular system [1]. It is one of the most devastating chronic diseases of the pulmonary circulation, which can be encountered by healthy individuals living in higher altitude, divers, mountain climber, athletes, and during exercise and rehabilitation [2]. It can also be found in patients in the setting of collagen vascular disease (e.g., localized cutaneous systemic sclerosis), portal hypertension, congenital left-to-right intracardiac shunts, infections with the human immunodeficiency virus (HIV), and persistent pulmonary hypertension of the newborn [3]. PAH can be defined clinically as a mean pulmonary arterial pressure of $\geq 25 \mathrm{mmHg}$ at rest or $\geq 30 \mathrm{mmHg}$ during exercise [4,5]. It can be attributed to combined effects of sustained vasoconstriction, concentric vascular remodeling, in situ thrombosis, and arterial wall stiffening, resulting in elevated pulmonary vascular resistance [5]. As a consequence, elevated pulmonary vascular resistance increases the right 
heart afterload and in the fullness of time results in right ventricular hypertrophy and eventually right heart failure and death [5].

The current therapies fall into several classes, including vasodilators, anticoagulants, antiplatelet agents, anti-inflammatory, and vascular-remodeling therapies [1,3]. Among these are vasodilative and antiproliferative drugs such as nitric oxide (NO), NO-donors, adenosine, calcium channel blockers (e.g., nifedipine, diltiazem), endothelin receptor antagonist (e.g., ambrisentan, bosentan, macitentan), phosphodiesterase inhibitors (sildenafil, tadalafil, vardenafil), prostacyclin and prostacyclin analogs (e.g., beraprost, epoprostenol, iloprost, and 2reprostinil), and guanylate cyclase stimulators (e.g., riociguat) [6]. Most of these drugs are administered to the patient either orally or intravenously leading to systemic side effects such systemic hypotension. The exceptions are two drugs, iloprost and 2reprostinil, which are inhaled therapies FDA-approved for human use in marketed pharmaceutical products as liquid inhalation aerosols delivered by nebulization [7]. There is a great unmet need to have more inhalation aerosol therapeutic drug delivery systems for targeted pulmonary delivery for the treatment of $\mathrm{PH}$.

Tetramethylpyrazine (TMP) (also known as Ligustrazine) is an active alkaloid contained in the rhizome of Ligusticum chuanxiong Hort, an herb that has been used for many years in China and Japan as an intravenous (i.v.) infusion solution for the treatment of occlusive cerebral arteriolar disease [8] and PAH [8,9]. It is a vasodilator [10] and its mechanism of action include calcium antagonism, cAMP production, and endotheliumdependent NO-mediated relaxation [9]. Furthermore, it has been reported that TMP could significantly decrease pulmonary hypertension caused by acute and chronic hypoxia in rats and ferrets in ex vivo isolated perfused lung model [11,12]. TMP has been shown to possess neuroprotective $[13,14]$ and anti-platelet functions [15]. The anti-inflammatory effect of TMP resulted in alleviating asthma in rodent models $[15,16]$. TMP has been shown to have protective lung effects against injury in acute lung injury (ALI) in a rat model of ALI [17]. The inhibitory effect of TMP on the RhoA/ROCK pathway $[17,18]$ is a uniquely distinct pharmacological mechanistic advantage in using TMP to treat $\mathrm{PH}$. The protective effect of TMP on endothelial dysfunction has been reported based on studying oxidative damage and mitochondrial dysfunction [19]. This antioxidant was shown to penetrate the skin when formulated for transdermal drug delivery for Alzheimer's treatment [20]. In addition, it has been shown to act as a Nrf2 activator (i.e., activates the Nrf/ARE pathway) in oxidative stress injury in vivo in rats [21]. Ligustrazine's antioxidant effects on lung fibrosis and ROS-related autophagy in an in vivo lung fibrosis model has been reported [22]. The antioxidant effects of ligustrazine in a pulmonary damage burn model has been studied [23].

Off-target systemic side effects are therapeutic-limiting due to systemic administration of the drug as an intravenous (i.v.) infusion acting on the systemic vascular circulatory system. Hence, a targeted approach to PH therapy would be to deliver the drug locally to the airways targeting the lung directly. Whereas i.v. drug administration is invasive, not patient-friendly, and causes a systemic high concentration in a short period of time leading to adverse side effects, localized pulmonary delivery by inhalation aerosols is non-invasive, patient-friendly, and would inherently require a reduced amount of drug to bring about the same therapeutic response [24,25]. Currently, Ventavis ${ }^{\circledR}$ (nebulized iloprost inhalation solution) and Tyvaso ${ }^{\circledR}$ (nebulized treprostinil inhalation solution) are the only FDA-approved inhalation products indicated for the treatment of PH. Ventavis ${ }^{\circledR}$ is delivered as a liquid aerosol through the I-neb nebulizer system and is used to treat both adult and pediatric populations [26]. Relatively long administration times for reaching the needed dose and the high frequency of dosing administration can lead to patient non-compliance with nebulized liquid inhalation products.

Hence, targeted pulmonary drug delivery by inhalation aerosol delivery is not only non-invasive but offers many significant advantages such as a large surface area for high drug absorption [27-29], a rapid onset of therapeutic action [24,30], low enzymatic activity [28,29,31], extensive blood supply [32], avoidance of first-pass metabolism [27,28,32], 
reduced dosing frequency [28], and reduced side effects [27,29,32]. There are added advantages unique to dry powder inhalers which are reduced administration time, reduced frequency of dosing administration, better physicochemical drug stability, more devices available that are versatile, small, lightweight, and portable without needing a power supply. Marketed DPI pharmaceutical products are approved by the FDA for use in children as young as 4 years old. In addition, the top-performing inhalation products on the market are dry powder inhalers due to clinically superior efficacy and high patient acceptance.

In this study, we report on the comprehensive characterization of the solid-state physicochemical properties of raw TMP and advanced spray dried TMP particles. In addition, this study reports on the in vitro aerosol dispersion properties of TMP dry powder aerosols using three different human dry powder inhaler devices varying in shear stress properties and in vitro cellular studies using human lung cells from different regions of the lung. Moreover, this study reports for the first time on the in vivo safety of inhaled TMP in healthy rats and in vivo efficacy of both liquid and dry powder inhalation aerosols in reducing the pulmonary arterial pressure in the validated monocrotaline (MCT) rat model of $\mathrm{PH}$.

\section{Experimental: Materials and Methods}

\subsection{Materials}

TMP ( $\geq 98 \%$ purity) $\left(\mathrm{C}_{8} \mathrm{H}_{12} \mathrm{~N}_{2}\right.$; molecular weight (MW): 136.19), shown in Figure 1 (ChemDraw ${ }^{\mathrm{TM}}$ Ultra Ver. 10.0; CambridgeSoft, Cambridge, MA, USA), was obtained from Sigma-Aldrich (St. Louis, MO, USA). Methanol (HPLC grade, ACS-certified grade, purity 99.9\%) was obtained from Fisher Scientific (Fair Lawn, NJ, USA). Hydranal ${ }^{\circledR}$-Coulomat AD was from Sigma-Aldrich (St. Louis, MO, USA). Resazurin sodium salt and DMSO LC-MS grade were from Thermo Scientific (Waltham, MA, USA). The nitrogen gas used was ultra-high purity (UHP) (Cryogenics and gas facility, The University of Arizona, Tucson, AZ, USA).

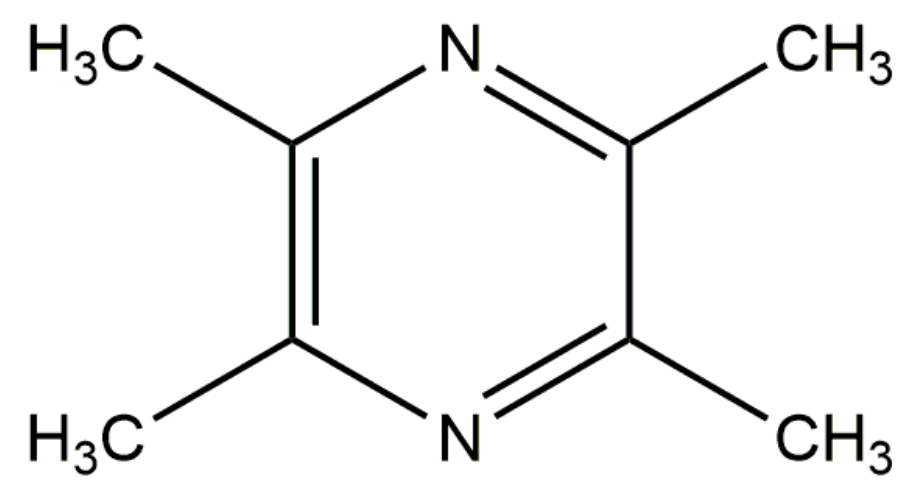

Figure 1. Chemical structure of tetramethylpyrazine (TMP) (ChemDraw ${ }^{\circledR}$ Ultra Ver. 10.0; CambridgeSoft, Cambridge, MA, USA).

\subsection{Methods}

2.2.1. Advanced Closed-Mode Spray Drying from Organic Solution

Spray drying (SD) was carried out using a B-290 Buchi mini spray dryer coupled with a B-295 inert loop and high-performance cyclone (Buchi Labortechnik AG, Flawil, Switzerland) in a closed-mode using compressed UHP dry nitrogen as the atomizing gas. The feed solution was prepared by dissolving $1 \% w / v$ drug TMP in methanol. A stainless steel nozzle with a diameter of $0.7 \mathrm{~mm}$ was used to atomize the drug solution. As listed in Table 1, the following conditions were used: atomization gas flow rate $670 \mathrm{~L} / \mathrm{h}(55 \mathrm{~mm})$, aspirator rate of $38 \mathrm{~m}^{3} / \mathrm{h}(100 \%)$, inlet temperature of $100{ }^{\circ} \mathrm{C}$ and feed rate of $27 \mathrm{~mL} / \mathrm{min}$. Spray-dried powders were stored in desiccators at $-20^{\circ} \mathrm{C}$ until further analysis. 
Table 1. Advanced spray drying parameters for spray dried (SD) TMP powders using methanol $(\mathrm{MeOH})$.

\begin{tabular}{cccc}
\hline $\begin{array}{c}\text { Feed Concentration } \\
(\% w / v)\end{array}$ & $\begin{array}{c}\text { Pump Rate (\% and } \\
\mathbf{m L} / \mathbf{m i n})\end{array}$ & Inlet T $\left({ }^{\circ} \mathbf{C}\right)$ & Outlet T $\left({ }^{\circ} \mathbf{C}\right)$ \\
\hline 1 & $90 / 27$ & $149-152$ & $18-25$ \\
\hline
\end{tabular}

\subsubsection{Scanning Electron Microscopy (SEM)}

Using similar conditions reported in previous studies [24,33], the drug particles as supplied (raw) and spray dried particles were imaged using SEM FEI Inspect S (Brno, Czech Republic) scanning electron microscope. Briefly, the samples were sputter coated with gold for $1.5 \mathrm{~min}$ and $15 \mathrm{mAmps}$ current using Anatech Hummer 6.2 (Union City, CA, USA) gold coater and imaged using $30 \mathrm{kV}$ accelerating voltage electron beam.

\subsubsection{Laser Diffraction Particle Sizing and Size Distribution}

Particle size and size distributions of the particles were determined by laser diffraction with the SALD-7101 (Shimadzu Scientific Instruments, Columbia, MD, USA) using conditions previously reported [34-37] for measurement of the mean size and size distribution of SD particles in aqueous suspension. Samples were dispersed in ultrapure water and ultrasonicated for $10 \mathrm{~s}$ in a water bath ultrasonicator (Branson 7500, Branson Ultrasonics, Danbury, CT, USA) before measuring particle size. The sample particle dispersion was immediately transferred to particle size measuring cell and kept stirring during measurement in nanoparticle size analyzer. The low refractive index of 1.50-0.00 i was used. Volume-based measurements obtained $\mathrm{D}_{\mathrm{V} 10}, \mathrm{D}_{\mathrm{V} 50}$, and $\mathrm{D}_{\mathrm{V} 90}$ were used as particle size characterization parameters. The Span value was calculated using the Equation (1) defined as:

$$
\text { Span }=\left[\left(\mathrm{D}_{\mathrm{V} 90}-\mathrm{D}_{\mathrm{V} 10}\right) / \mathrm{D}_{\mathrm{V} 50}\right]
$$

\subsubsection{X-ray Powder Diffraction (XRPD)}

Using similar conditions reported by previous studies [24,33], X-ray powder diffraction (XRPD) patterns of samples were collected with $\mathrm{Cu} \mathrm{K} \alpha$ radiation $(45 \mathrm{kV}, 40 \mathrm{~mA}$, and $\lambda=1.5406 \AA$ ) between $10.0^{\circ}$ and $80.0^{\circ}(2 \theta)$ with a scan rate of $2.00^{\circ}$ per minute at ambient temperature using PanAnalytical X'pert diffractometer (PANalytical Inc., Westborough, MA, USA).

\subsubsection{Differential Scanning Calorimetry (DSC)}

Thermal analysis and phase transitions measurements were performed using differential scanning calorimeter (DSC) TA Q1000 differential scanning calorimeter (DSC) (TA Instruments, New Castle, DE, USA) with RSC90 automated cooling system similar to previous conditions $[24,33]$. Samples weighing $1-3 \mathrm{mg}$ of the test powder were used with a hermetic T-Zero ${ }^{\circledR}$ DSC pans for melting $\left(\mathrm{T}_{\mathrm{m}}\right)$ and enthalpy $(\Delta \mathrm{H})$ measurements. The pans were heated between $0{ }^{\circ} \mathrm{C}$ to $150{ }^{\circ} \mathrm{C}$ at a heating scanning rate of $5.00^{\circ} \mathrm{C} / \mathrm{min}$. All measurements were made in triplicate.

\subsubsection{Hot-Stage Microscopy (HSM) under Cross-Polarizers}

Using similar conditions reported previously [24,33], hot-stage microscopy (HSM) was performed using Leica DMLP cross-polarized microscope (Wetzlar, Germany) equipped with a Mettler FP 80 central processor heating unit and Mettler FP82 hot stage (Columbus, $\mathrm{OH}, \mathrm{USA})$. Powder samples were mounted on a cover glass slide and heated from $25.0^{\circ} \mathrm{C}$ to $100.0^{\circ} \mathrm{C}$ at a heating rate of $5.00{ }^{\circ} \mathrm{C} / \mathrm{min}$. Images were captured periodically.

\subsubsection{Karl Fischer Titration (KFT)}

The residual water content of spray dried powder was analytically quantified by Karl Fisher (KF) coulometric titration using a TitroLine 7500 trace titrator (SI Analytics, Yellow 
Springs, OH, USA) similar to previous studies [24,33]. Approximately 1-10 mg of powder was added directly into the reaction cell that contained Hydranal ${ }^{\circledR}$ coulomat AD reagent.

\subsubsection{Raman Spectroscopy}

Spectroscopy of the raw and spray-dried powders was carried by-non-invasive and non-destructive Raman spectroscopy for molecular fingerprinting with a Renishaw InVia Reflex (Gloucestershire, UK) at the surface using a 20× magnification objective on a Leica DM2700 optical microscope (Wetzlar, Germany) and equipped with a Renishaw inVia Raman system (Gloucestershire, UK) using similar conditions previously reported [24,33, 38,39]. Raman spectra were obtained at $514 \mathrm{~nm}$ laser excitation using a $20 \times$ magnification objective lens.

\subsubsection{In Vitro Aerosol Dispersion Performance}

In vitro aerosol dispersion study was conducted in accordance with US Pharmacopeia (USP) Chapter $<601>$ specification [40] on aerosols and using conditions similar to those previously reported [24,33]. The Next-Generation Impactor ${ }^{\circledR}\left(\mathrm{NGI}^{\circledR}\right)$ (Copley Scientific, Nottingham, UK) with a stainless steel induction port (USP throat) attachment was used at a flow rate of $60 \mathrm{~L} / \mathrm{min}$ with an actuation time of $10 \mathrm{~s}$ through the inhaler device. The aerosol dispersion performance was tested using three different FDA-approved human unit-dose capsule-based inhaler devices varying in shear stress properties. These three human DPI devices are namely: a low-shear stress device, the Aerolizer ${ }^{\circledR}$ (Merck, Whitehouse Station, NJ, USA); a medium-shear stress device, the Neohaler ${ }^{\circledR}$ (Sunovion Pharmaceuticals Inc, Marlborough, MA, USA); and a high-shear stress device, the HandiHaler ${ }^{\circledR}$ (Boehringer Ingelheim, Ingelheim, Germany). Quali-V clear HPMC size 3 inhalation-grade capsules (Qualicaps, RTP, NC, USA) were filled with about $10 \mathrm{mg}$ of powder. Critical quality attributes of aerosols such as fine particle dose (FPD), fine particle fraction with respect to nominal dose (FPFND), fine particle fraction with respect to emitted dose (FPFED), and emitted dose (ED) were calculated using the following Equations (2)-(5):

$$
\begin{gathered}
\text { FPD }=\text { Mass of particles deposited on stages } 2 \text { to } 7 \\
\text { FPFND }=\frac{\text { FPD }}{\text { Initial particle mass loaded in capsules }} \times 100 \% \\
\text { FPFED }=\frac{\text { FPD }}{\text { Total particle mass on all stages }} \times 100 \% \\
\mathrm{ED}=\frac{\text { Initial mass in capsules }- \text { Final mass remaining in capsules }}{\text { Initial mass in capsules }} \times 100 \%
\end{gathered}
$$

\subsubsection{In Vitro Human Cell Viability}

Human pulmonary cell lines for cellular studies were purchased from the American type culture collection ATCC ${ }^{\circledR}$ A549 $\left(\right.$ ATCC $^{\circledR}$ CCL-185 ${ }^{\mathrm{TM}}$ ), H358 (ATCC ${ }^{\circledR}$ CRL-5807 ${ }^{\mathrm{TM}}$ ) and Calu-3 (ATCC ${ }^{\circledR}$ HTB-55 ${ }^{\mathrm{TM}}$ ). A549 and H358 were grown in Dulbecco's modified eagle's medium (DMEM) Advanced 1X supplemented with fetal bovine serum (FBS), Pen-Strep, Fungizone ${ }^{\circledR}$, and L-glutamine obtained from Gibco ${ }^{\circledR}$ by Life Technologies (Thermo Fisher Scientific Inc., Hanover Park, IL, USA). Calu-3 cell line was grown in Eagle's minimum essential medium (EMEM) obtained from ATCC supplemented with FBS, Pen-Strep and Fungizone $^{\circledR}$ obtained from Gibco ${ }^{\circledR}$ by Life Technologies (Thermo Fisher Scientific Inc., USA).

Cell-based assays are often used to determine if test molecules have effects on cell proliferation or cell death. The A549 pulmonary cell line is a human alveolar epithelial lung adenocarcinoma cell line for the deep lung small airways (respiratory region) and often used as an in vitro human cellular model of the alveolar type II pneumocyte cell in in vitro pulmonary drug delivery and metabolism studies. The H348 pulmonary cell line is a human bronchioalveolar epithelial cell line from the deep lung small airways 
(respiratory region) and expresses lung surfactant-associated protein A (SP-A) [25]. Both cell lines were grown in a growth medium including Dulbecco's modified eagle's medium (DMEM) advanced $1 \times, 10 \%(v / v)$ fetal bovine serum (FBS), Pen-Strep $(100 \mathrm{U} / \mathrm{mL}$ penicillin, $100 \mu \mathrm{g} / \mathrm{mL})$, Fungizone $(0.5 \mu \mathrm{g} / \mathrm{mL}$ amphotericin $\mathrm{B}, 0.41 \mu \mathrm{g} / \mathrm{mL}$ sodium deoxycholate), and $2 \mathrm{mM}$ L-Glutamine in a humidified incubator at $37^{\circ} \mathrm{C}$ and $5 \% \mathrm{CO}_{2}$.

As previously reported [41], both cell lines were seeded in 96-well plates at 5000 cells/well and $100 \mu \mathrm{L} /$ well and allowed to attach for $48 \mathrm{~h}$. Then, the cells were exposed to $100 \mu \mathrm{L}$ of TMP dissolved in media at different concentrations and incubated for $72 \mathrm{~h}$ after exposure. Continuously, $20 \mu \mathrm{L}$ of $10 \mu \mathrm{M}$ resazurin sodium salt dissolved in $1 \%$ DMSO in media was added to each well and incubated for $4 \mathrm{~h}$. At this point, the fluorescence intensity was detected at $544 \mathrm{~nm}$ (excitation) and $590 \mathrm{~nm}$ (emission) using a Synergy H1 Multi-Mode Reader (BioTek Instruments Inc., Winooski, VT, USA). The relative viability of each sample was calculated as follows:

$$
\text { Relative viability }(\%)=\frac{\text { Sample fluorescence intensity }}{\text { Control fluorescence intensity }} \times 100 \%
$$

\subsubsection{In Vitro Transepithelial Electrical Resistance (TEER)}

Calu-3 lung epithelial cells, a human lung adenocarcinoma cell line derived from the bronchial submucosal large airway region, were grown in a growth medium including Eagle's minimum essential medium (EMEM) (obtained from ATCC), 10\% $(v / v)$ fetal bovine serum (FBS), Pen-Strep (100 U/mL penicillin, $100 \mu \mathrm{g} / \mathrm{mL})$, Fungizone $(0.5 \mu \mathrm{g} / \mathrm{mL}$ amphotericin $\mathrm{B}, 0.41 \mu \mathrm{g} / \mathrm{mL}$ sodium deoxycholate) in a humidified incubator at $37^{\circ} \mathrm{C}$ and $5 \% \mathrm{CO}_{2}$, as previously reported [24]. The cells were seeded at 500,000 cells $/ \mathrm{mL}$ in Costar Transwells ${ }^{\circledR}(0.4 \mu \mathrm{m}$ polyester membrane, $12 \mathrm{~mm}$ for a 12 -well plate, Corning, NY, USA) with $0.5 \mathrm{~mL}$ of media on the apical side and $1.5 \mathrm{~mL}$ of media on the basolateral side. Media was changed every other day from the basolateral and apical side. After 10 days of growth, when the cells reached a TEER value of about $1000 \Omega / \mathrm{cm}^{2}$ which is an indicator of a confluent monolayer at liquid covered culture (LCC) the media was removed from both sides and $800 \mu \mathrm{L}$ of media was added to the basolateral side of the transwells to facilitate air-interface culture (AIC) conditions. The TEER responses of the cells were measured with an Endohom $12 \mathrm{~mm}$ Culture Cup (World Precision Instruments, Sarasota, FL, USA). For TEER measurement, $0.5 \mathrm{~mL}$ of media was added to the apical side of the Transwell $5 \mathrm{~min}$ before measurement and then immediately removed to return the cells to AIC conditions. After the TEER values reached $500 \Omega / \mathrm{cm}^{2}$ (indicating a confluent monolayer at AIC conditions), the cells were exposed to $100 \mu \mathrm{M}$ of SD TMP and representative co-SD formulations dissolved in non-supplemented EMEM media. The liquid aerosol formulations were delivered to the Calu-3 cells at AIC using the Penn Century MicroSprayer ${ }^{\circledR}$ Aerosolizer-Model IA-1B. TEER values were then recorded for up to 7 days after aerosol treatment, as previously reported [24,42].

\subsubsection{In Vivo Efficacy in PH-Induced Rats}

In vivo studies were conducted in the monocrotaline (MCT) rat model of $\mathrm{PH}$, a validated in vivo PH disease animal model, for testing inhaled TMP efficacy in decreasing PH. TMP was administered as an inhaled liquid aerosol in one study and as an inhaled spray-dried powder aerosol in a separate study. All rats were purchased from Charles River Laboratories International Inc. (Wilmington, MA, USA) and were weighed weekly to monitor their health. PH was induced by injecting $60 \mathrm{mg} / \mathrm{kg}$ of MCT dissolved in phosphate buffered saline (PBS) intraperitoneally (IP injection).

Inhaled liquid aerosol study description: A total of 25 male Sprague Dawley rats, each weighing in the range of 260-294 g, were used in this study. The animals were divided into 5 groups $(n=5)$ into the following categories: Group 1 Naïve (control); Group 2 Naïve + TMP; Group 3 Naïve + vehicle (drug-free solvent); Group 4 MCT (PH-induced); and Group $5 \mathrm{MCT}+$ treated with TMP. Two weeks after MCT administration, the rats began inhaled aerosol treatment of an aerosolized liquid formulation of TMP using the Penn-Century 
MicroSprayer ${ }^{\circledR}$ Aerosolizer-Model IA-1B (Penn-Century, Inc, Wyndmoor, PA, USA) for 14 days. Each animal received 500 microliters of liquid TMP formulation. For the first few days, the animals received a dose of $100 \mathrm{mg} / \mathrm{kg}$ of TMP dissolved in $100 \%$ ethanol vehicle, but there were some unforeseen death in the study. Hence from day 4 , the remaining animals received a dose of $10 \mathrm{mg} / \mathrm{kg}$ of TMP dissolved in a vehicle comprised of $10 \%$ ethanol $+90 \%$ PBS. The vehicle group animals received the respective solvent systems used to dissolved TMP. Right ventricle systolic pressure (RVSP) hemodynamics were performed at the end of 14 days drug treatment by inserting a customized pressure transducer catheter (SPR-513, Millar Instruments, Houston, TX, USA), into the right ventricle (RV) via the right jugular vein and right atrium. The transducer was connected to a Millar Transducer Control Unit TC-510 and PL3504 PowerLab 4/35 data acquisition system (AD Instruments, Inc., Colorado Springs, CO, USA). At the end of pressure recording, the animals were euthanized.

Inhaled spray-dried powder aerosol study description: A total of 30 male Sprague Dawley rats, each weighing in the range of 280-350 g, were used in this study. The animals were divided into 5 groups $(n=5)$ into the following categories: Group 1 Naïve (control); Group 2 Naïve + TMP; Group 3 MCT (PH-induced); Group 4 MCT+ treated with vehicle (air); and Group $5 \mathrm{MCT}+$ treated with TMP. Two weeks after MCT IP injection, the rats started to receive treatment via aerosolization of a dry powder formulation of SD TMP (10 mg $/ \mathrm{kg}$ dose) using the Penn-Century Dry Powder Insufflator ${ }^{\mathrm{TM}}-$ Model DP-4R (Penn Century Inc., Wyndmoor, PA, USA), the dry powder inhaler delivery device customized for the respiratory tract of the rat, for 14 days. RVSP hemodynamics measurements were made similar to the liquid aerosol study. However, the measurements were performed at 2 weeks and 4 weeks after MCT administration to establish that the disease was induced. At the end of pressure recording, the animals were euthanized.

All animal studies were performed in accordance with Institutional Animal Care \& Use Committee (IACUC) guidelines for the care and use of laboratory animals under the protocol approved by University of Arizona Institutional Animal Care \& Use Committee.

\subsubsection{Statistical Analysis}

All experiments were performed in at least triplicate $(n=3)$ unless otherwise mentioned. All data were statistically analyzed using Sigma Plot 13.0 (Systat Software Inc., San Jose, CA, USA). Unpaired student t-test and one-way analysis of variance (ANOVA) were performed to compare the statistical significance of the test groups. $p$ value $\leq 0.050$ was considered to be statistically significant.

\section{Results}

\subsection{Scanning Electron Microscopy (SEM)}

The particle shape and surface morphology were visualized by SEM as shown in Figure 2 for raw TMP and SD TMP. SD TMP exhibited oblong and relatively smooth morphology compared to raw TMP.

\subsection{Laser Diffraction Particle Sizing}

Laser diffraction sizing experiments were carried out on spray dried particles. The particles size distribution from the laser diffraction was in the range of 4-14 $\mu \mathrm{m}$. The average values of Dv10, Dv50 and Dv90 were 4.186 $\pm 0.701,6.156 \pm 1.47$ and $14.552 \pm$ $4.928 \mu \mathrm{m}$, respectively. The Span value was calculated to be $1.684 \pm 0.645$.

\subsection{X-ray Powder Diffraction (XRPD)}

The XRPD pattern of raw TMP showed sharp and intensive peaks at $2 \theta$-degree values of $16.36^{\circ}, 24.78^{\circ}, 36.35^{\circ}, 37.37^{\circ}, 40.75^{\circ}, 45.03^{\circ}, 48.58^{\circ}$ and $50.89^{\circ}$ characteristic of long-range molecular order (i.e., crystallinity) as shown in Figure 3. SD TMP had intensive peaks at $16.56^{\circ}, 19.00^{\circ}, 24.83^{\circ}$, and $27.56^{\circ}$ indicative of the retention of crystallinity following spray drying. It is notable that the SD TMP particles, unlike raw TMP, did not exhibit any peak 
in the $2 \theta$ region of $30-60^{\circ}$. This is suggestive of a possible polymorphic conversion from the raw TMP crystalline form following spray drying under these conditions.

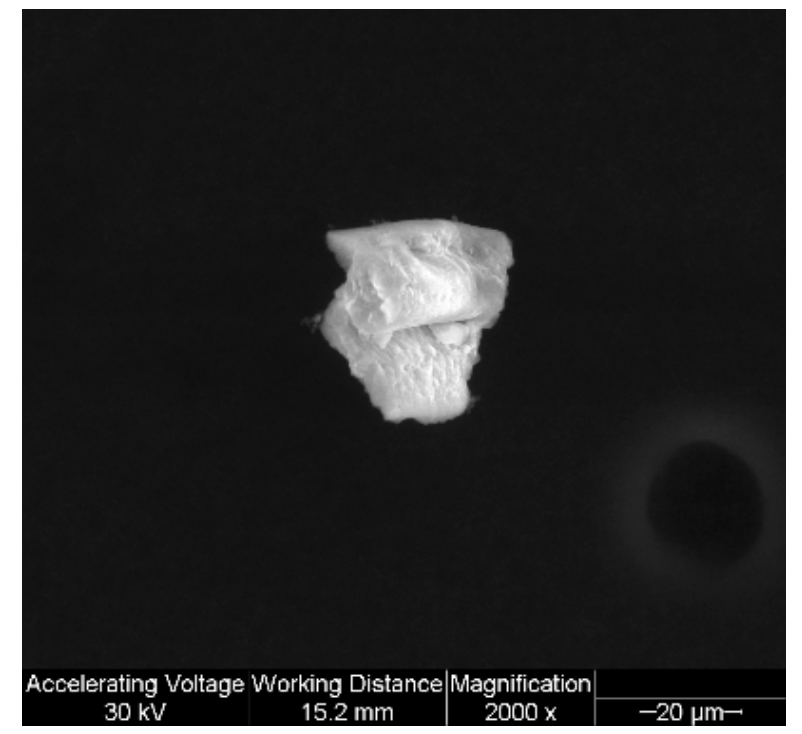

(a)

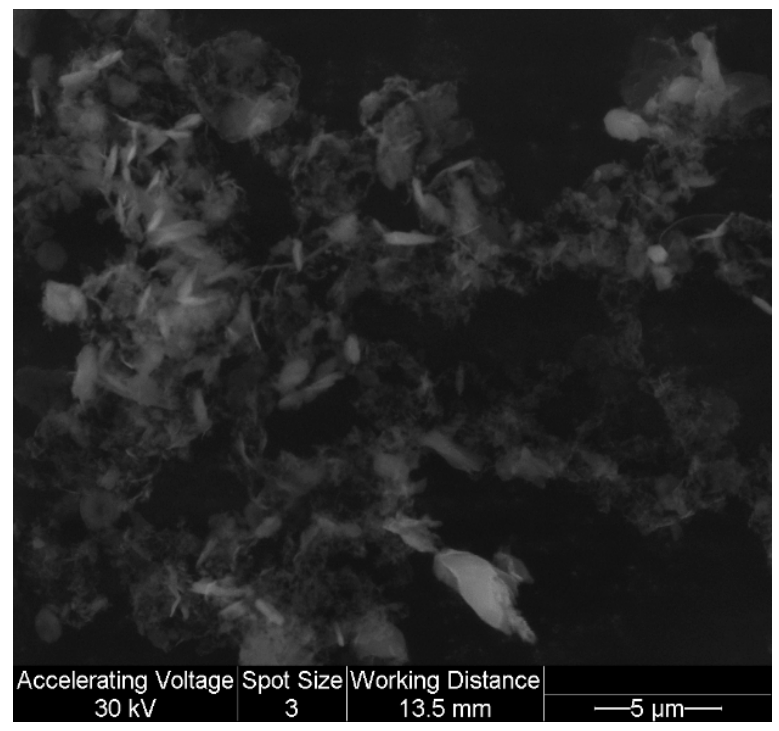

(b)

Figure 2. Scanning electron micrographs of: (a). raw TMP (magnification 2000×) and (b). SD TMP (magnification 10,000×).

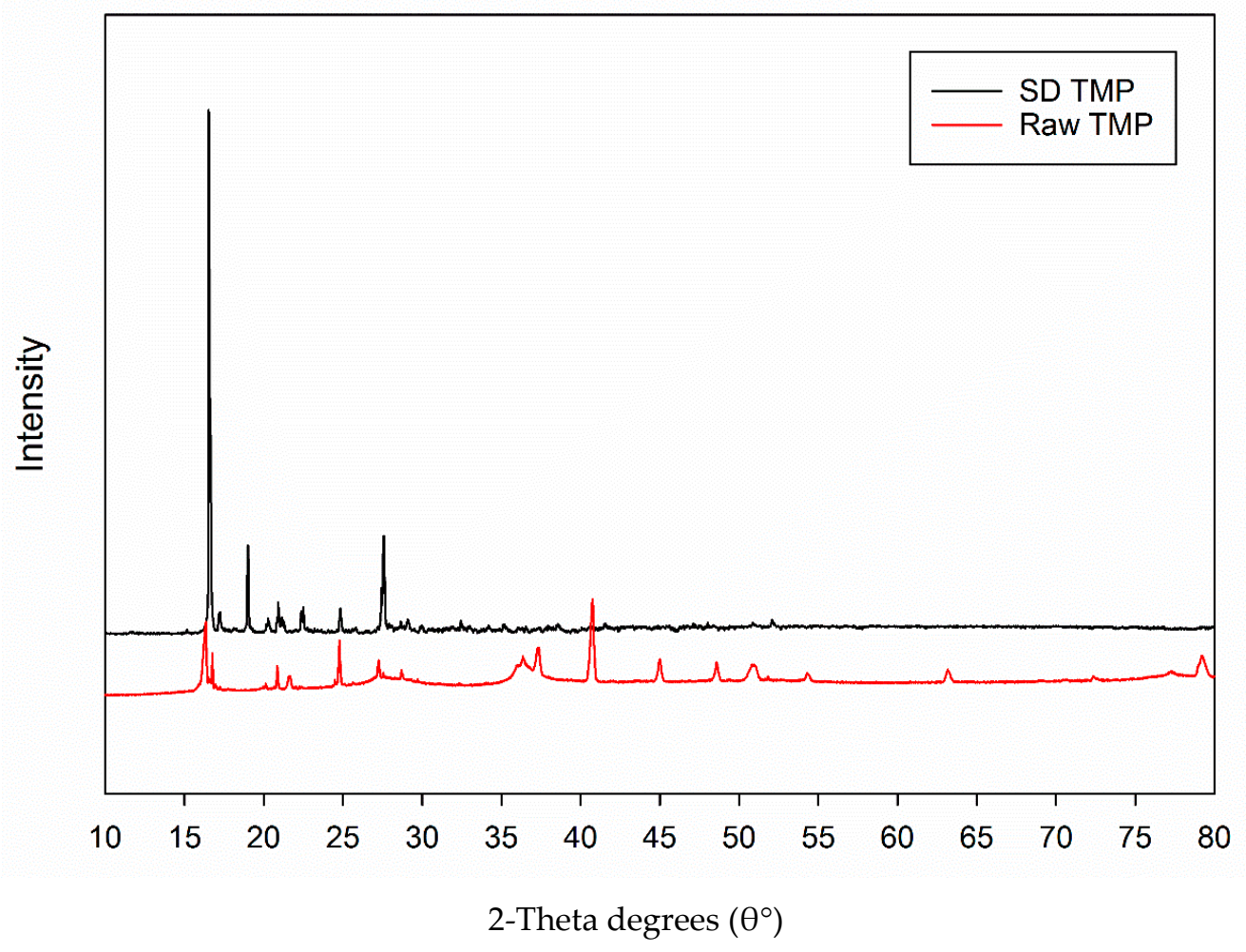

Figure 3. X-ray powder diffractograms of raw TMP and SD TMP. 


\subsection{Differential Scanning Calorimetry (DSC)}

DSC of the raw TMP and spray dried TMP showed in Figure 4 has a single transition at around $85^{\circ} \mathrm{C}$. The single endotherm seen in the thermogram suggests that TMP is crystalline with a melting point around $85^{\circ} \mathrm{C}$.

Raw TMP

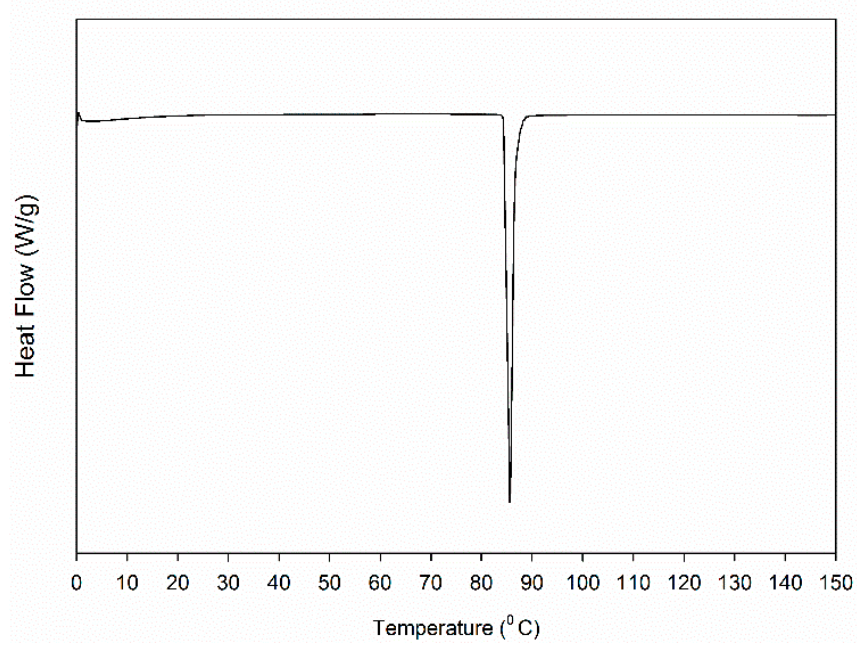

(a)

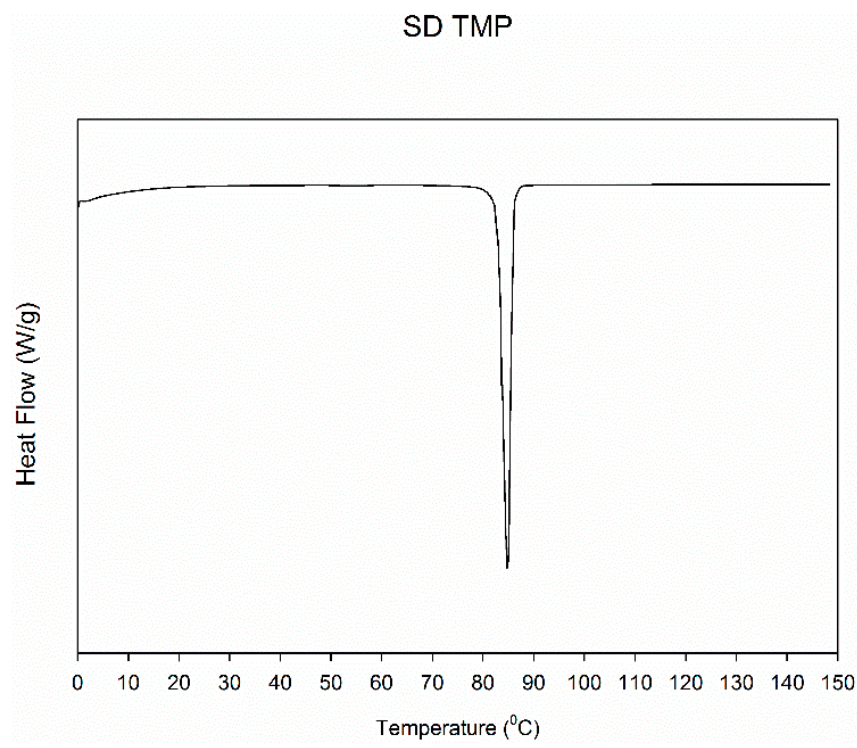

(b)

Figure 4. DSC thermograms of: (a) Raw TMP and (b) SD TMP (Exothermic peak is upward; Endothermic peak is downward).

\subsection{Hot-Stage Microscopy (HSM) under Cross-Polarizer Lens}

Raw TMP and SD TMP particles were visualized under cross-polarized light, as seen in Figure 5, and both exhibited birefringence, which is a characteristic feature of crystals. Upon heating the particles at a constant heating rate, raw TMP particles started melting at approximately $62{ }^{\circ} \mathrm{C}$ and completely melted at approximately $86^{\circ} \mathrm{C}$. While the SD TMP particles started melting around $60^{\circ} \mathrm{C}$ and completely melted around $86^{\circ} \mathrm{C}$. This is consistent with DSC thermal analysis. 


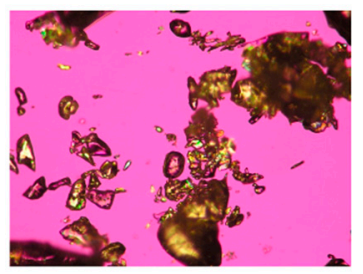

$25^{\circ} \mathrm{C}$

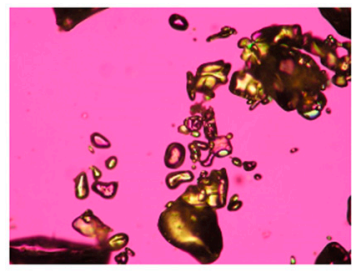

$76^{\circ} \mathrm{C}$

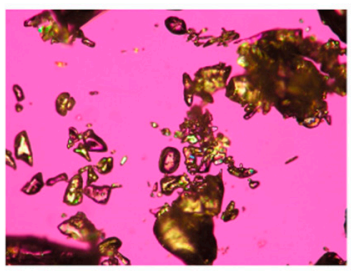

$37^{\circ} \mathrm{C}$

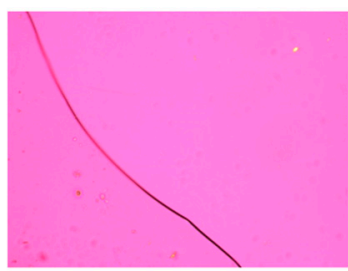

$86^{\circ} \mathrm{C}$

(a)

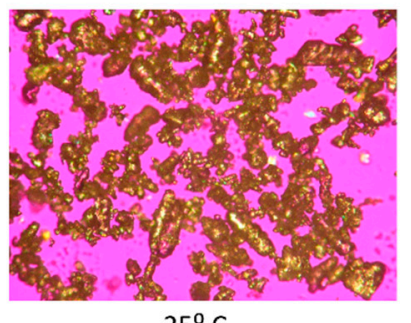

$25^{\circ} \mathrm{C}$
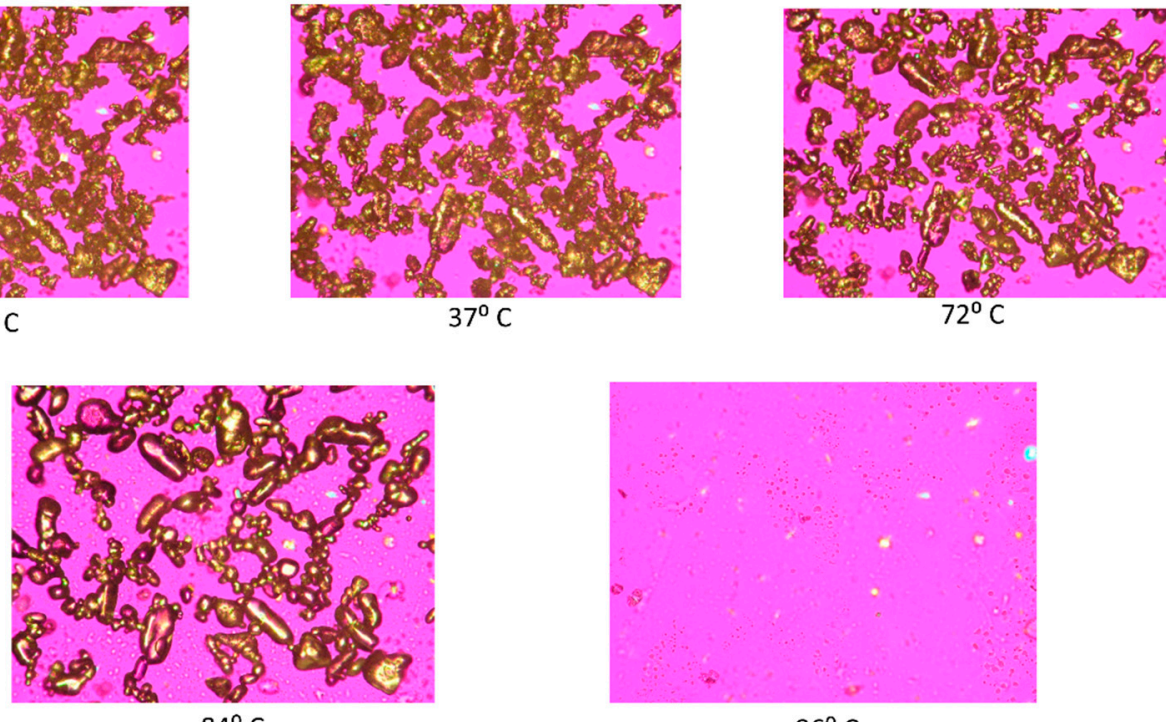

$86^{\circ} \mathrm{C}$

(b)

Figure 5. Hot-stage micrographs of (a) Raw TMP and (b) Spray Dried (SD) TMP.

\subsection{Karl Fischer Titration (KFT)}

The residual water content in the powder using Karl Fischer titration was $0.633 \pm$ $0.251 \% w / w$ for raw TMP. However, the SD TMP had a lower water content of $0.368 \pm$ $0.103 \% w / w$ which can be attributed to the spray drying process. Table 2 lists the KFT values for raw and SD TMP powders. 
Table 2. Physical properties of raw TMP and spray dried (SD) TMP. ( $n=3$, Mean \pm SD).

\begin{tabular}{ccc}
\hline Physical Properties & Raw TMP & SD TMP \\
\hline & & $\mathrm{D}_{\mathrm{v} 10}=4.186 \pm 0.701 \mu \mathrm{m}$ \\
Particle Sizes & $\mathrm{N} / \mathrm{A}$ & $\mathrm{D}_{\mathrm{v} 50}=6.156 \pm 1.147 \mu \mathrm{m}$ \\
& & $\mathrm{D}_{\mathrm{v} 90}=14.552 \pm 4.928 \mu \mathrm{m}$ \\
$\left(\mathrm{D}_{\mathrm{v}}\right)$ & & $\mathrm{Span}=1.684 \pm 0.645 \mu \mathrm{m}$ \\
\hline Phase Transitions & $\mathrm{T}_{\mathrm{m}}=85.93 \pm 0.71^{\circ} \mathrm{C}$ & $\mathrm{T}_{\mathrm{m}}=85.11 \pm 0.36{ }^{\circ} \mathrm{C}$ \\
\hline$\left(\mathrm{T}_{\mathrm{m}}\right.$ and $\left.\Delta \mathrm{H}\right)$ & $\Delta \mathrm{H}=152.5 \pm 5.27 \mathrm{~J} / \mathrm{g}$ & $\Delta \mathrm{H}=149.2 \pm 7.91 \mathrm{~J} / \mathrm{g}$ \\
\hline Residual Water Content & $0.633 \pm 0.251 \% w / w$ & $0.368 \pm 0.103 \% w / w$ \\
\hline
\end{tabular}

\subsection{Raman Spectroscopy}

From Figure 6, the raw TMP and SD TMP have similar molecular fingerprinting spectra suggesting that the TMP molecule remained the same before and after spray drying. Prominent peaks were seen at $714 \mathrm{~cm}^{-1}, 1286 \mathrm{~cm}^{-1}, 1547 \mathrm{~cm}^{-1}$ and between $2900-3000 \mathrm{~cm}^{-1}$ wavenumbers. The sharp peaks seen in this spectra concurs with the inference of TMP crystallinity before and after spray drying.

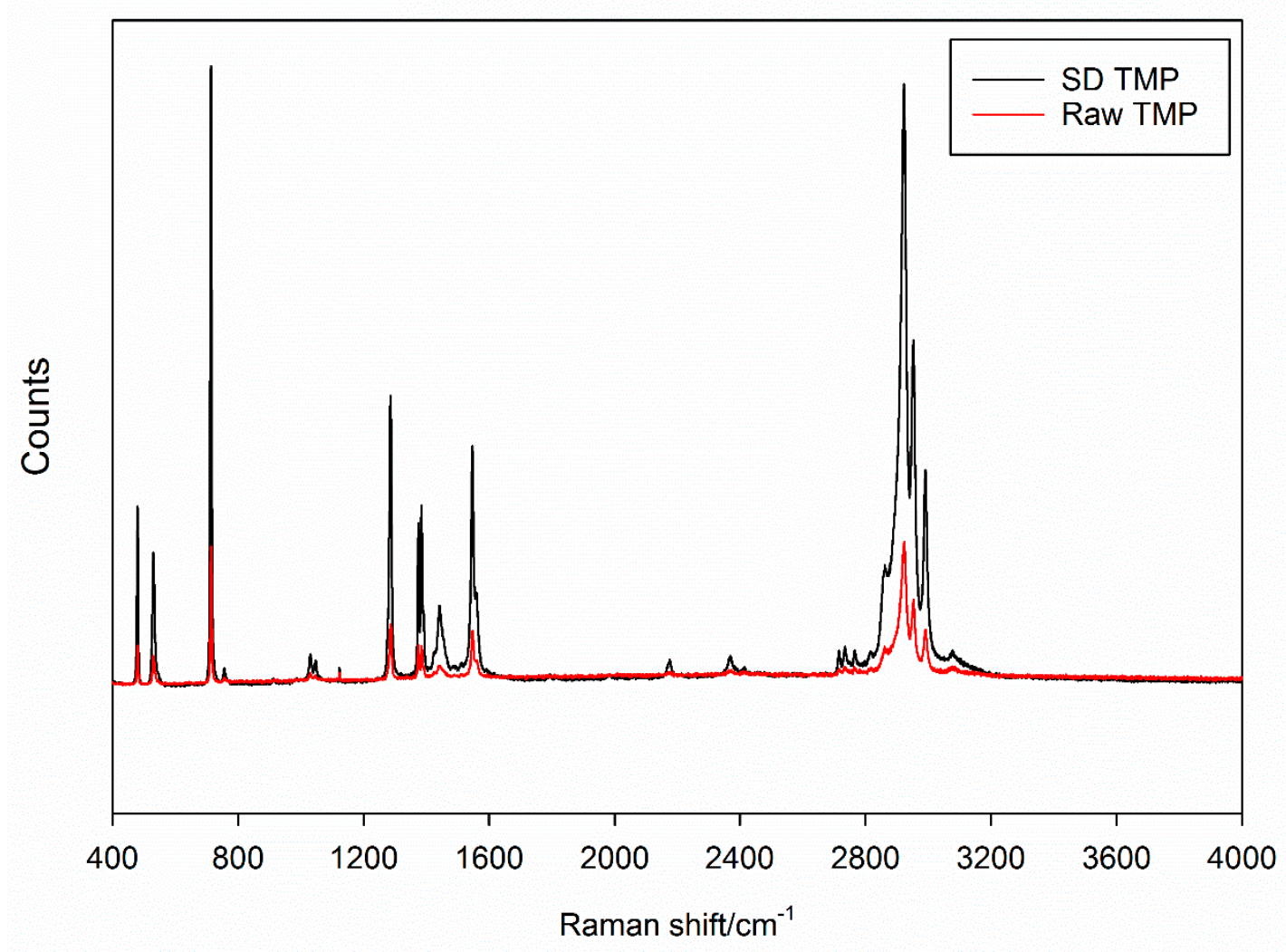

Figure 6. Raman spectra of raw TMP and spray dried (SD) TMP.

\subsection{In Vitro Aerosol Dispersion Performance}

The aerosol dispersion performance of SD TMP using the three unit-dose capsulebased inhaler devices with varying shear stress properties is listed in Table 3. The NGI stage deposition using different human DPI devices is exhibited in Figure 7. The ED from the high-resistance HandiHaler ${ }^{\circledR}$, (Boerhinger Ingelheim, Ingelheim, Germany) device was $100 \%$, while the other two devices emitted $88 \%$ of the loaded powder from the capsules. The FPFND values were $1.41 \%, 4.36 \%$ and $3.33 \%$ for the Aerolizer ${ }^{\circledR}$ (Novartis AG, Basel, 
Switzerland), Neohaler ${ }^{\circledR}$ (Novartis Pharma Stein AG, Stein, Switzerland), and HandiHaler ${ }^{\circledR}$ (Boerhinger Ingelheim, Ingelheim, Germany), respectively.

Table 3. In vitro aerosol dispersion performance parameters for spray dried TMP particles using human dry powder inhaler (DPI) devices Aerolizer ${ }^{\circledR}$, Neohaler $^{\circledR}$ and Handihaler ${ }^{\circledR}$ at $60 \mathrm{~L} / \mathrm{min}$. $(n=3$, Mean $\pm \mathrm{SD})$.

\begin{tabular}{|c|c|c|c|}
\hline Inhaler Device & Emitted Dose (\%) & $\begin{array}{c}\text { Fine Particle Dose with } \\
\text { Respect to Nominal } \\
\text { Dose (mg) Fine Particle } \\
\text { Fraction with Respect to } \\
\text { Nominal Dose (FPFND) } \\
(\%)\end{array}$ & $\begin{array}{c}\text { Fine Particle Dose with } \\
\text { Respect to Emitted Dose } \\
\text { (mg) Fine Particle } \\
\text { Fraction with Respect to } \\
\text { Emitted Dose (FPFED) } \\
(\%)\end{array}$ \\
\hline \multirow{2}{*}{ Handihaler $^{\circledR}$} & \multirow{2}{*}{$100 \pm 2.03$} & 3.33 & 37.24 \\
\hline & & $3.83 \pm 0.42$ & $8.9 \pm 3.87$ \\
\hline \multirow{2}{*}{ Neohaler ${ }^{\circledR}$} & \multirow{2}{*}{$88.41 \pm 6.70$} & 3.48 & 25.19 \\
\hline & & $4.36 \pm 0.65$ & $14.87 \pm 7.30$ \\
\hline \multirow{2}{*}{ Aerolizer ${ }^{\circledR}$} & \multirow{2}{*}{$88.76 \pm 7.27$} & 1.15 & 8.16 \\
\hline & & $1.41 \pm 0.57$ & $14.86 \pm 8.0$ \\
\hline
\end{tabular}

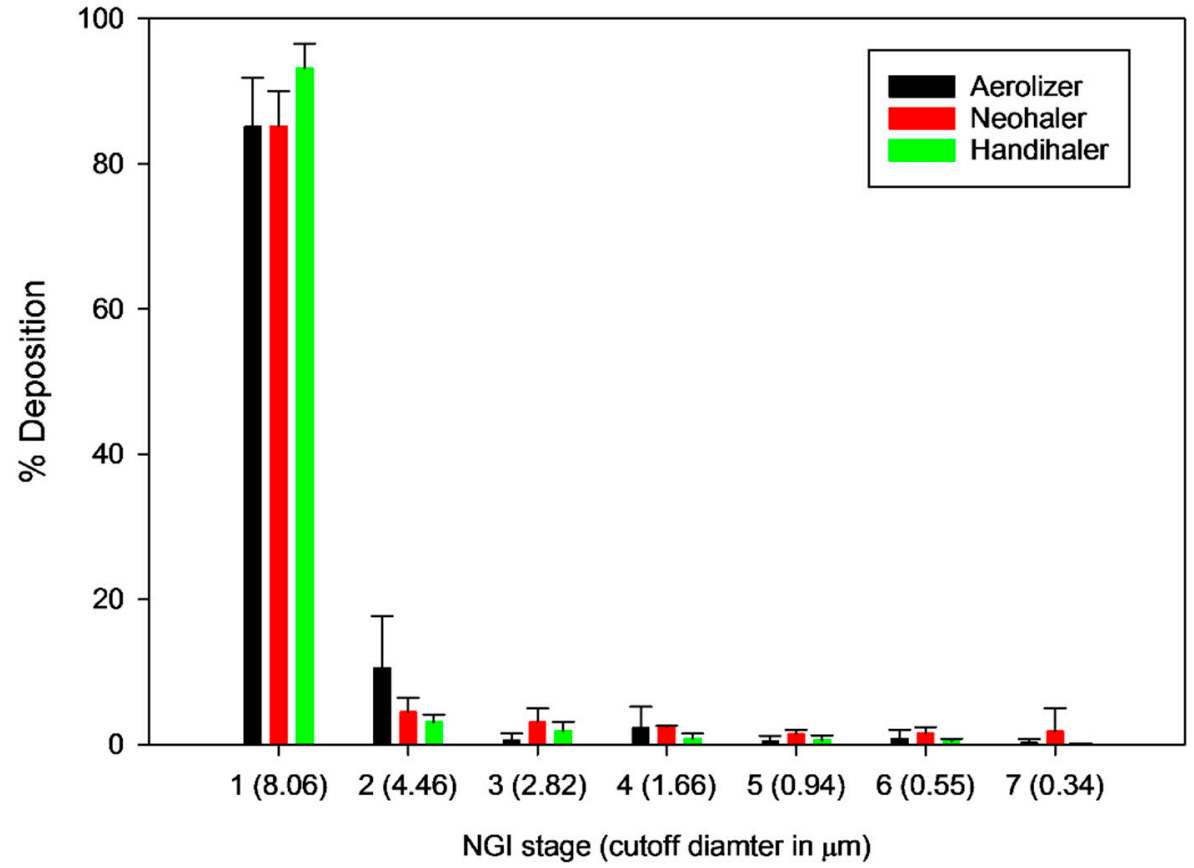

Figure 7. In vitro aerosol deposition of spray dried TMP particles using human dry powder inhaler (DPI) devices Aerolizer ${ }^{\circledR}$, Neohaler $^{\circledR}$ and Handihaler ${ }^{\circledR}$ using $\mathrm{NGI}^{\circledR}$ at $60 \mathrm{~L} / \mathrm{min}$ flow rate. $(n=3$, mean $\pm \mathrm{SD})$.

\subsection{In Vitro Human Cell Viability}

In vitro cell viability assay was performed on pulmonary cell lines A549 and H358. Molar concentrations of $1 \mu \mathrm{M}, 10 \mu \mathrm{M}, 100 \mu \mathrm{M}$, and $1000 \mu \mathrm{M}$ of raw TMP and SD TMP were tested after dissolving the drug in media. The relative cell viability of A549 cell line was $100 \%$ for both raw TMP and SD TMP at all concentrations. The relative viability of H358 cell line was 100\% for SD TMP, however, at higher concentrations, the viability was decreased. The cell viability using different drug concentrations is shown in Figure 8. 
Cell Viability -A549

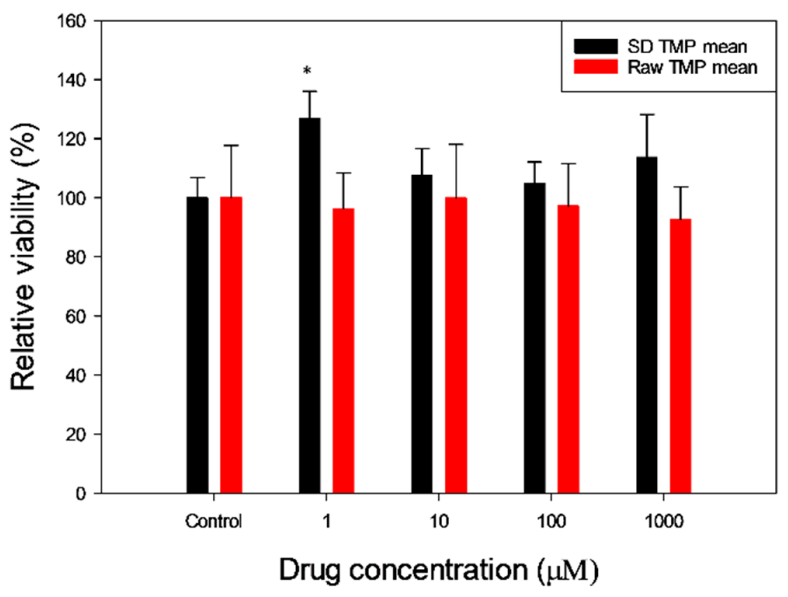

(a)
Cell Viability H358

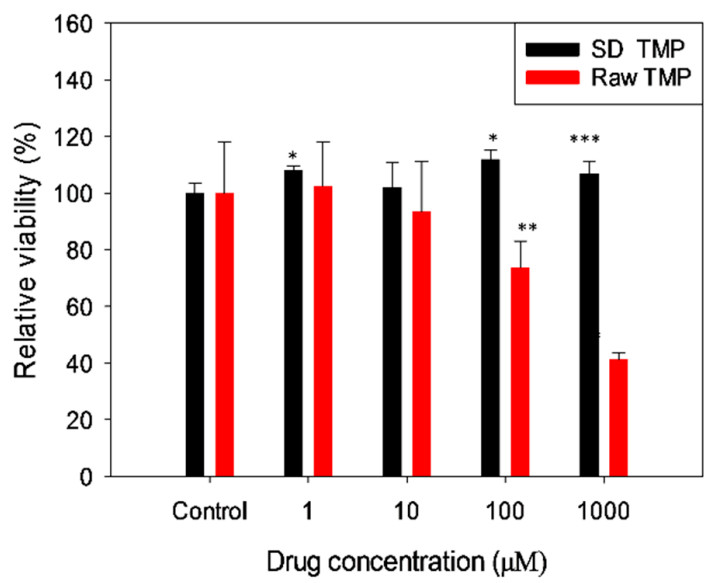

(b)

Figure 8. In Vitro Vell Viability of: (a). A549 and (b). H358 human pulmonary cell lines. ${ }^{*} p$ value $<0.001,{ }^{* *} p$ value 0.010 , *** $p$ value 0.015. $(n=6$, Mean $\pm \mathrm{SD})$.

\subsection{In Vitro Transepithelial Electrical Resistance (TEER)}

It can be seen from Figure 9 that three hours after treatment of the cells with $100 \mu \mathrm{M}$ of SD TMP as a liquid aerosol using the Microsprayer ${ }^{\circledR}$ Aerosolizer (Penn-Century, Wyndmoor, PA, USA), the electrical resistance decreased, however on continuous culturing for seven days following the treatment, the resistance was regained. Calu-3 cells treated with the vehicle (10\% ethanol $+90 \%$ EMEM non-supplemented media) had a similar trend of decreased resistance three hours after liquid aerosol treatment, followed by gradual increase in the resistance over a period of time.

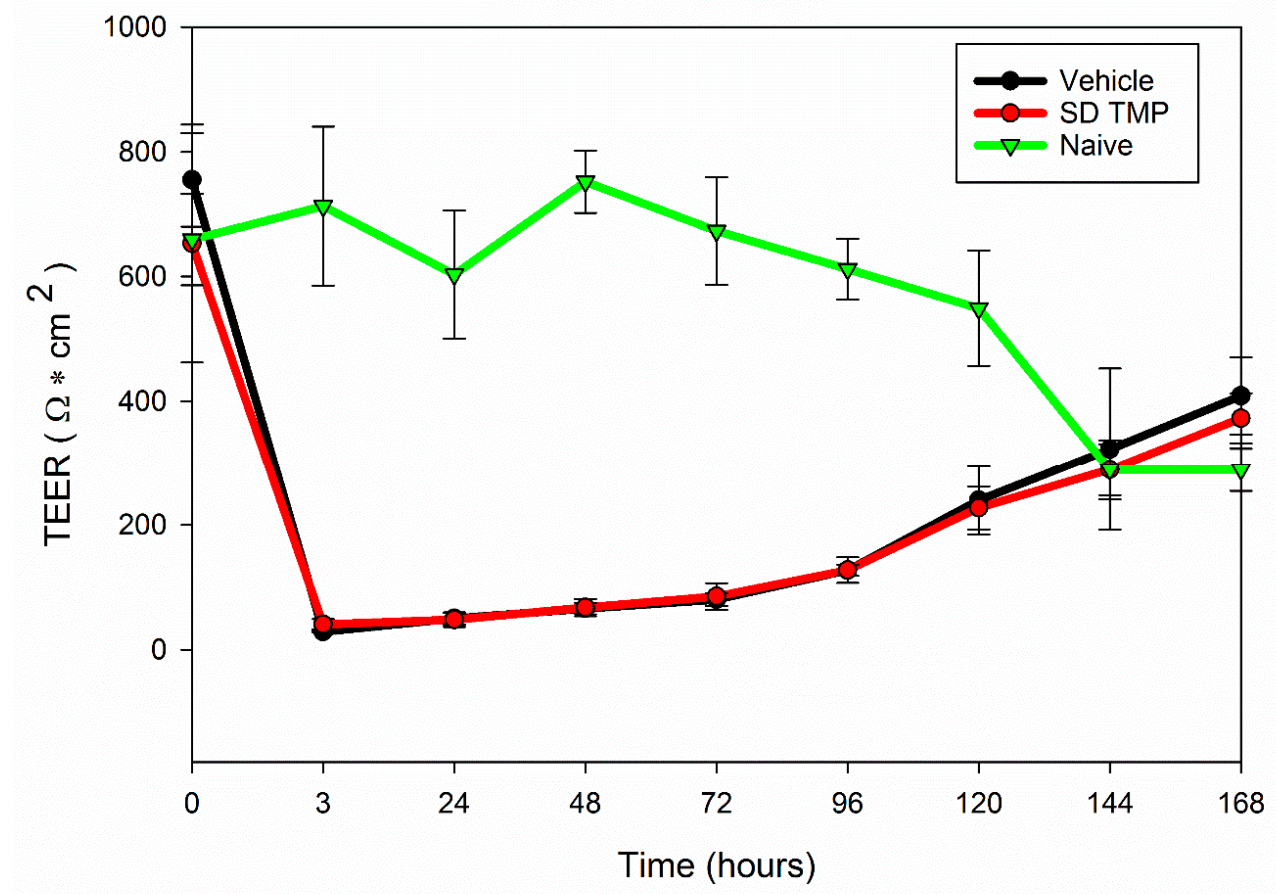

Figure 9. In Vitro transepithelial electrical resistance (TEER) measurements using human Calu-3 bronchial epithelial cell line exposed to representative liquid aerosol formulations in air-interface culture (AIC) conditions using Microsprayer ${ }^{\circledR}$ Aerosolizer. $(n=3$, mean \pm SD). 


\subsection{In Vivo Efficacy Study}

The rat's body weight plots in Figure 10 shows a loss of weight with time for the Groups 4 and 5 that received MCT. In contrast, the Group 1 (Naïve) rats showed a steady increase in body weight with time (Figure 10). As it is presented in Figure 11 and Table 4, the RVSP measurements in Group 1 (Naïve), Group 2 (Naïve+ TMP) and Group 3 (Naïve+ vehicle) are ranging between $20-25 \mathrm{mmHg}$ (normal $\mathrm{RV}$ pressure in rats). Four weeks after MCT administration, the RVSP increased more to $80-100 \mathrm{mmHg}$ in the untreated Group 4 suggesting that the animals had severe PH. As can be seen from Figure 11, after four weeks of treatment with TMP as liquid aerosol (Group 5) the RVSP significantly decreased by 20-30 units of $\mathrm{mmHg}$ relative to Group 5 (4 weeks).

Group 1: Naive (Control)

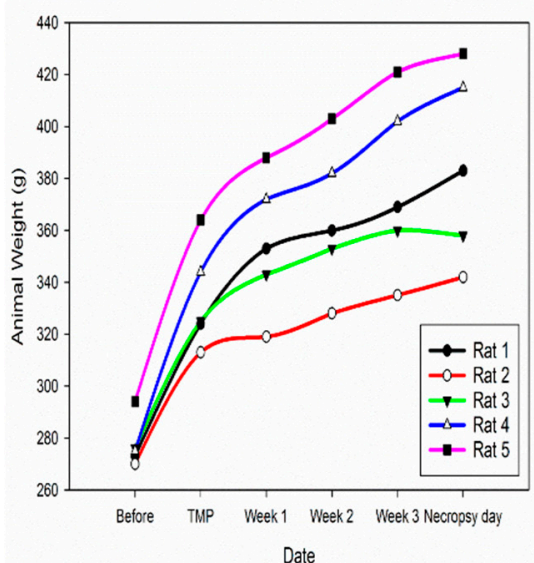

Group 4 : MCT (PH induced)

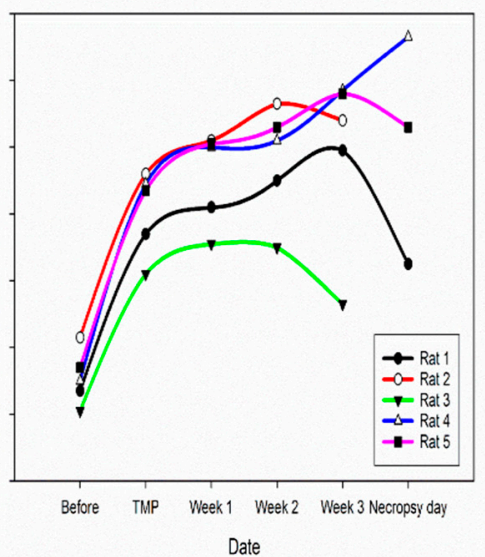

Group 5: MCT+TMP microsprayer

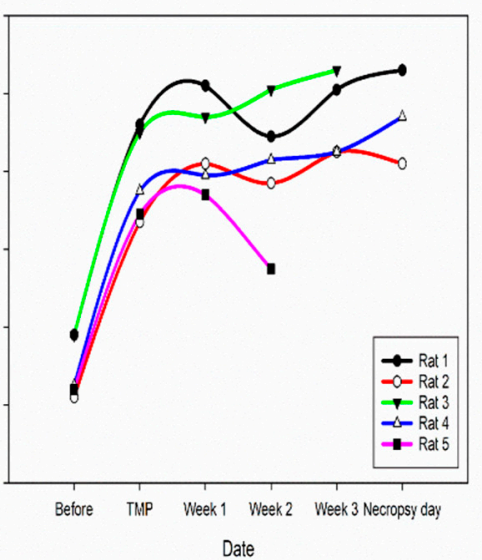

Figure 10. Body weights of rats measured weekly for Groups 1, 4 and 5 from Microsprayer ${ }^{\circledR}$ Aerosolizer (liquid aerosol) study.
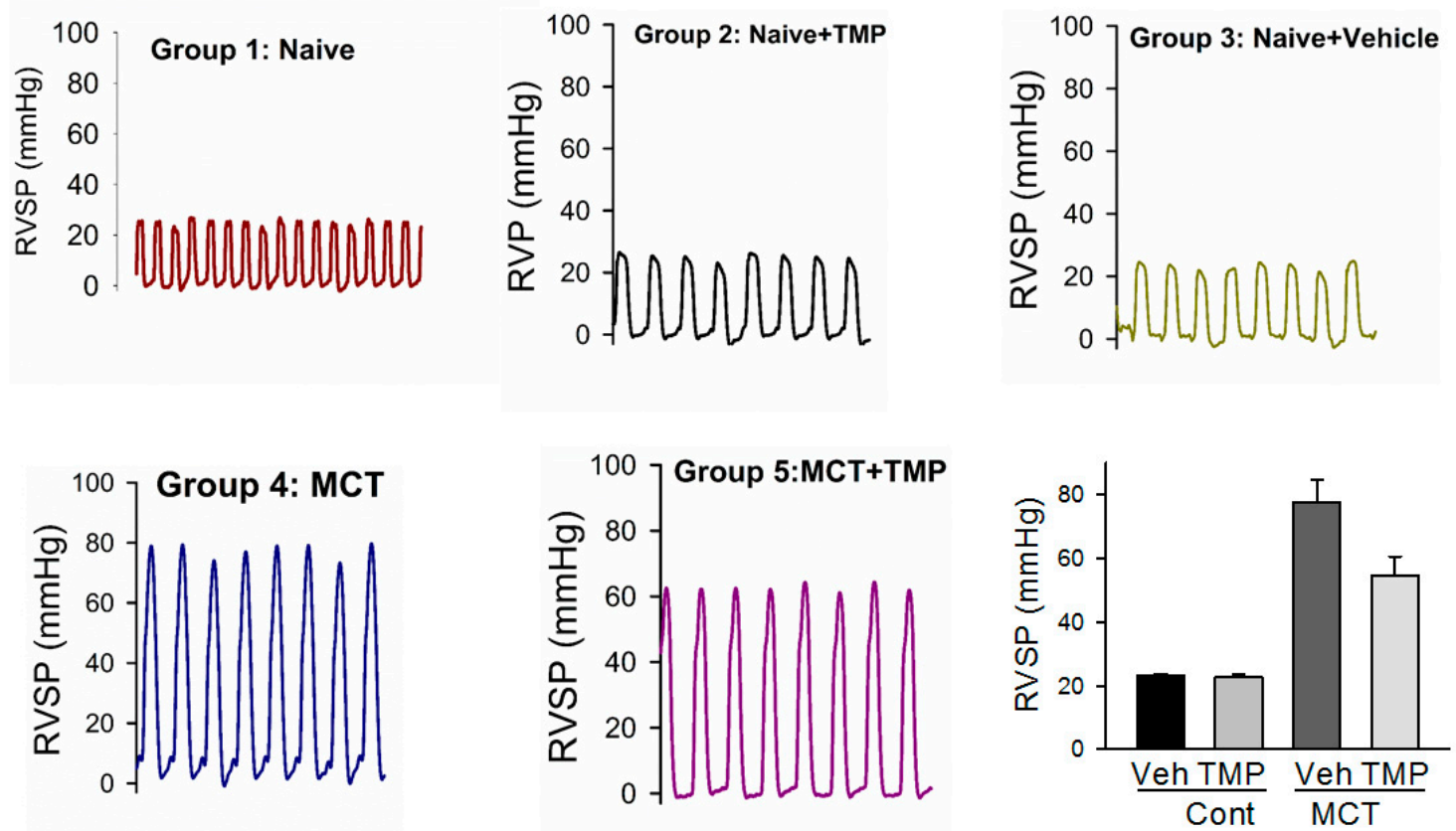

Figure 11. Representative in vivo right ventricle systolic pressure (RVSP) measurements of different rat groups from Microsprayer ${ }^{\circledR}$ Aerosolizer (liquid aerosol) study. 
Table 4. In vivo right ventricle pressure hemodynamic measurements from microsprayer (liquid aerosol) study.

\begin{tabular}{cccc}
\hline $\begin{array}{c}\text { Control + Vehicle } \\
\text { Group (mm Hg) }\end{array}$ & $\begin{array}{c}\text { Control + TMP } \\
\text { Group (mm Hg) }\end{array}$ & $\begin{array}{c}\text { MCT Group (mm } \\
\text { Hg) }\end{array}$ & $\begin{array}{c}\text { MCT + TMP Group } \\
\text { (mm Hg) }\end{array}$ \\
\hline 23.6567 & 23.8947 & 94.1697 & 61.1996 \\
\hline 23.7513 & 22.9558 & 60.2783 & 43.1133 \\
\hline 20.6622 & 19.0997 & 78.0645 & 60.1284 \\
\hline 24.0879 & 24.6036 & 78.5773 & N/A \\
\hline 23.6379 & N/A & N/A & N/A \\
\hline
\end{tabular}

The rat body weight plots in Figure 12 clearly show a significant loss of weight with time for the Groups 4 and 5 that received MCT. In contrast, Group 1 (Naive) rats showed a steady increase in body weight with time (Figure 12). As shown in Figure 13 and Table 5, the RVSP hemodynamic measurements in Groups 1 (Naïve) and 2 (Naïve+ TMP) are ranging between 20-25 mmHg (normal RV pressure in rats). Two weeks after MCT administration, the RVSP considerably increased to a range of $40-50 \mathrm{mmHg}$, as can be seen in Figure 13B. Four weeks after MCT administration, the RVSP increased even more to a range of $80-100 \mathrm{mmHg}$ in the untreated Group 3. It is evident from the Figure $13 \mathrm{~B}$ hat after two weeks of aerosol treatment with SD TMP (Group 5) the RVSP significantly decreased by $\sim 20-30 \mathrm{mmHg}$ relative to Group 3 (4 weeks). It is important to note that the insufflator device used to administer the powder had no effect on the RVSP of Group 4 rats (data not shown).

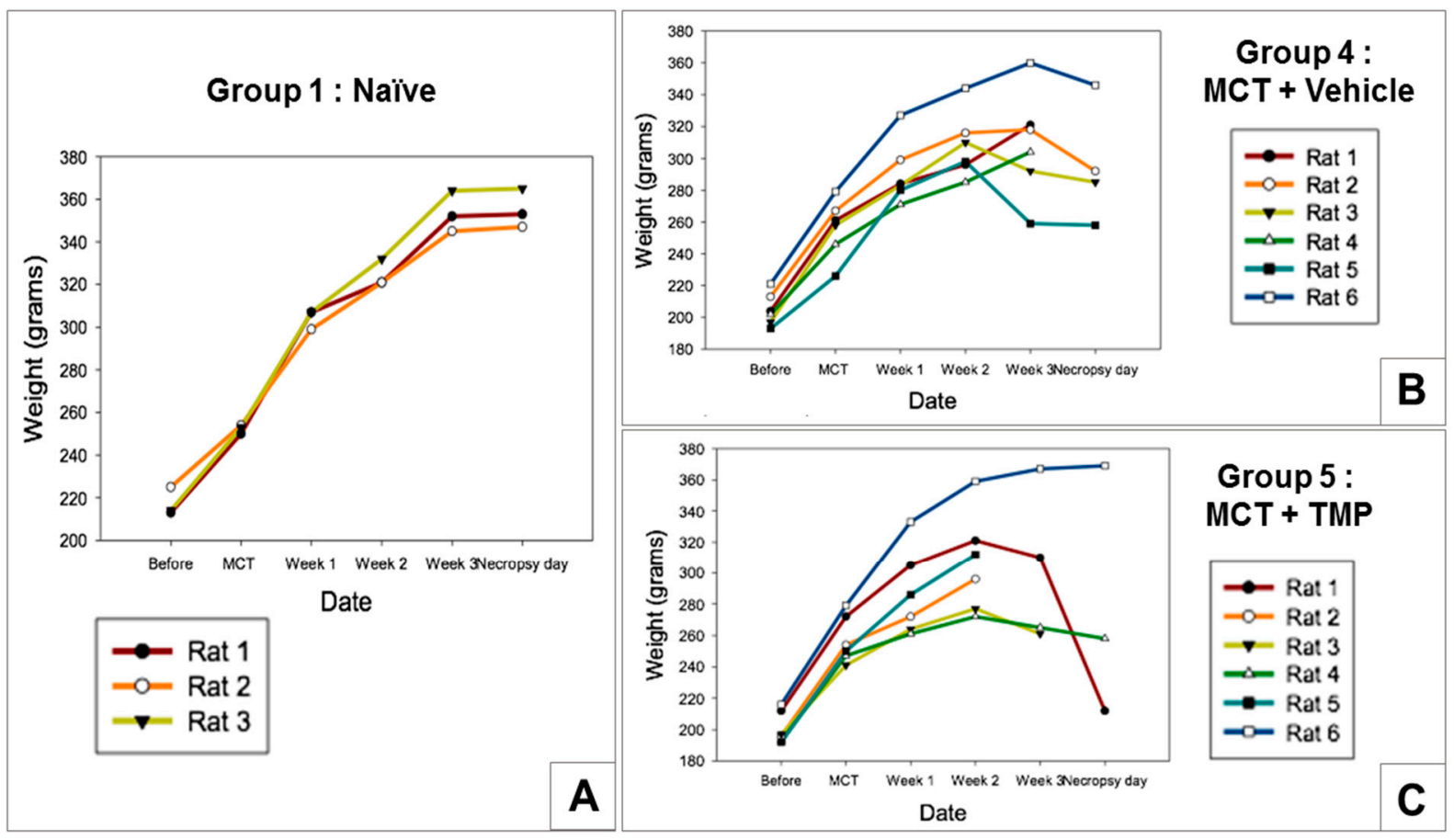

Figure 12. Body weights of rats measured weekly for: (A) Group 1; (B) Group 4; and (C) Group 5 from insufflator (dry powder aerosol) study. 


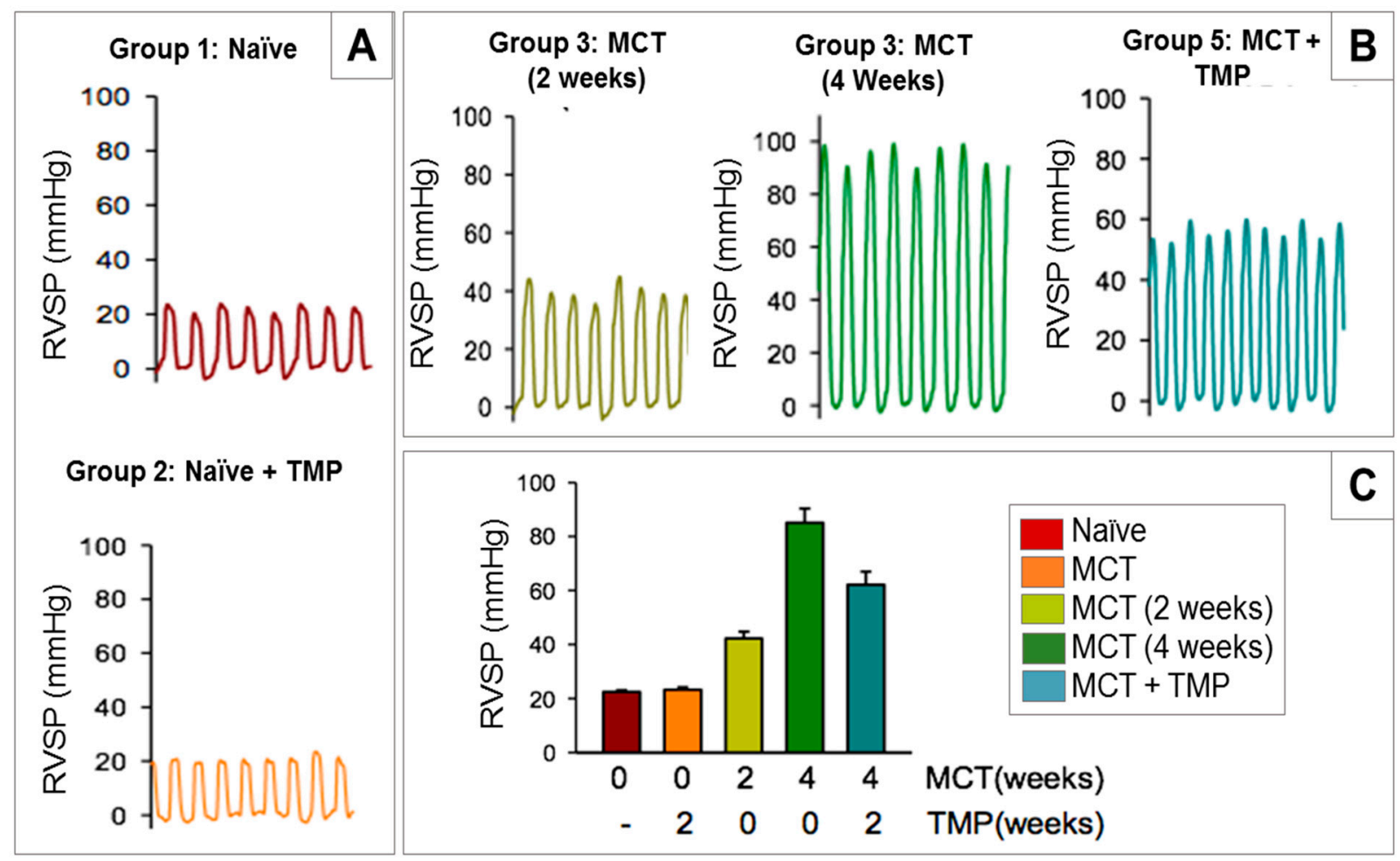

Figure 13. Representative in vivo right ventricle systolic pressure (RVSP) measurements of: (A). Groups 1 \& 2; (B) Groups 3 $\& 5$; and (C) pressure measurement comparison between different rat groups from insufflator (dry powder aerosol) study.

Table 5. In vivo right ventricle pressure hemodynamic measurements from insufflator (powder aerosol) study.

\begin{tabular}{ccccc}
\hline $\begin{array}{c}\text { Control (mm } \\
\text { Hg) }\end{array}$ & $\begin{array}{c}\text { Control + TMP } \\
\text { Group (mm Hg) }\end{array}$ & $\begin{array}{c}\text { MCT (2 Weeks) } \\
\text { Group (mm Hg) }\end{array}$ & $\begin{array}{c}\text { MCT (4 Weeks) } \\
\text { Group (mm Hg) }\end{array}$ & $\begin{array}{c}\text { MCT + TMP } \\
\text { Group (mm Hg) }\end{array}$ \\
\hline 22.5330 & 20.8110 & 39.4080 & 97.6720 & 78.2010 \\
\hline 21.9020 & 24.2410 & 52.0390 & 95.7920 & 70.5310 \\
\hline 20.9950 & 23.8990 & 38.4880 & 90.0360 & 58.6830 \\
\hline 19.3520 & 24.7030 & 41.0640 & 95.1610 & 62.4200 \\
\hline 22.3220 & 26.0550 & 40.3810 & 79.8910 & 43.3890 \\
\hline 23.6890 & 19.6940 & N/A & 78.3780 & 59.8200 \\
\hline
\end{tabular}

\section{Discussion}

This is the first report on TMP development and formulation as dry powder aerosols using advanced organic closed-mode spray drying process (Table 1). The spray dried particles were comprehensively characterized to test their suitability for pulmonary drug delivery. From the results obtained in the in vitro human cellular studies on cell viability and TEER seen in Figures 8 and 9, respectively, it is seen that the spray-dried TMP formulation at various concentrations is non-cytotoxic and biocompatible with human pulmonary cells from different regions of the lungs including the respiratory deep lung region. It was observed that possibly a polymorphic conversion occurred following spray drying based on XRPD analysis (Figure 3). This is evident from the lack of peaks in the XRPD diffractogram (Figure 3) between $2 \theta$-degree values of $30-50^{\circ}$. Previously Zhang et al., reported [43] the X-ray diffraction pattern of ligustrazine that is similar to the raw TMP diffraction pattern reported in our present study. However, when TMP was formulated with a PLGA diblock polymeric carrier, the crystallinity changed depending on the extent 
of miscibility of TMP with PLGA diblock copolymer. Hence, other crystal forms of TMP (i.e., polymorphs) may possibly exist.

In our study, advanced spray drying under the described conditions generally caused a disruption in the crystallinity of TMP often rendering it non-crystalline (i.e., amorphous). Our group has previously reported crystallinity retention by polymorphic interconversion following advanced spray drying [44]. Spray drying is a high-throughput engineering technology that designed and produces the particles tailored for pulmonary inhalation aerosols to be in the desired size range, shape and surface property $[27,34,35,39,45-48]$. The particle sizing data using laser diffraction (Table 2) and in vitro NGI aerosol dispersion performance (Figure 7) show that the size range of SD TMP particles readily aerosolize and are in the inhalable size range. The particle morphology is non-spherical and surface morphology is smooth for TMP particles, as seen in the SEM micrographs (Figure 2).

The aerosol dispersion of such particles is expected to be influenced by the shear stress property of the DPI device that is used to generate the aerosol [49-53] and the dry powder interparticulate interactions [30,54]. The DPI device design, specific resistance and shear stress caused by the device have a great impact on the improved or diminished performance of the aerosol formulation [55]. We tested three different FDA-approved human DPI devices to examine the influence of the device type (low-, medium-, or high-shear stress) on in vitro aerosol performance of SD TMP particles. From the NGI impactor data (Figure 7 and Table 3), it can be seen in Figure 7 that the particle deposition in the early stages of NGI is higher than the later stages. One-way ANOVA tests showed statistical significance between the FPFND of Aerolizer ${ }^{\circledR}$ versus HandiHaler $^{\circledR}(p=0.006)$ and Aerolizer $^{\circledR}$ versus Neohaler $^{\circledR}$ $(p=0.010)$. The same test showed no statistical significant difference between the FPFND of Neohaler ${ }^{\circledR}$ when compared with HandiHaler ${ }^{\circledR}(p=0.378)$. Similarly, the ED from the three devices had no statistically significant $(p=0.103)$ differences.

It can be inferred from the mass deposition data that the maximum fine particle dose that can be achieved using this formulation will be $3.48 \mathrm{mg}$ using Neohaler ${ }^{\circledR}$, a medium-shear stress DPI device. The high-shear stress DPI device (HandiHaler $\left.{ }^{\circledR}\right)$ and the medium-shear stress DPI device $\left(\right.$ Neohaler $\left.^{\circledR}\right)$ achieved similar fine particle doses while the low-shear stress device (Aerolizer ${ }^{\circledR}$ ) gave a relatively lower FPD. This suggests that, in addition to the turbulence created in the dry powder inhaler, there are other inhaler device factors that can influence the aerosolization and deaggregation of the SD TMP particles.

SD TMP did not significantly affect the cell viability of both A549 and H358 human pulmonary cell lines (Figures 7 and 8) representing the deep lung respiratory region of the lungs. Hence, this suggests that the drug over a wide dose range is non-cytotoxic and biocompatible on these cells. The TEER analysis (Figure 8) showed that the TMP-treated Calu-3 cells regained resistance similarly as the cells treated with the vehicle. There was no statistical difference between the vehicle and the SD TMP. After 7 days, the final resistance reached by all untreated (naïve), vehicle-treated and SD TMP-treated cells were statistically similar. This finding showed that the monolayer recovery happens as early as six days. The loss of electrical resistance and recovery suggests a reversible process, which in turn, ensures the integrity of the cellular barrier and further suggesting non-cytotoxicity and biocompatibility on these cells.

The in vivo data (Tables 4 and 5, and Figures 10-13) showed that the MCT model successfully achieved PH in the rodent after two weeks of administration via intraperitoneal (IP) injection. The RVSP significantly increased after four weeks of MCT administration as it was reported previously [37]. In general, the results from both the insufflator and microsprayer study suggest that TMP is effective in preventing the progression of $\mathrm{PH}$. The study design included a liquid aerosol, in addition to powder, since the dissolution of TMP powder in airway fluids had not been previously reported. Moreover, the influence of the liquid state vs. dry powder state on inhalation treatment efficacy is important.

The body weight plots of the rats showed development of the disease, as can be seen in Figures 10 and 12, where MCT-induced PH rats lost weight with time. In contrast, naïve rats gained weight with time and maintained the weight as it was expected. Regarding the 
RVSP values (Tables 4 and 5, Figures 11 and 13), it was noticed that groups 1 and 2 rats with and without drug (TMP) treatment maintained a pressure of $\sim 25 \mathrm{mmHg}$ after four weeks, which is normal in naïve rats. After two weeks of the MCT injection, an increase in the RVSP pressure is observed. After four weeks, the increase in the RVSP reveals severe $\mathrm{PH}$. This was observed in both the liquid and powder aerosol studies indicating that MCT is a suitable model for PH therapeutics study. It is seen in Figures 10 and 12 that the treatment of the rats with inhaled TMP as both powder and liquid aerosols for 2 weeks has a remarkable impact on the significant decrease of RVSP pressure. For both the inhaled liquid aerosol of TMP and the advanced spray-dried DPI of TMP, the RVSP measurements of the drug-treated groups were in the range of $60 \mathrm{mmHg}$, while the diseased animal model was $80 \mathrm{mmHg}$. For the first time, this study demonstrates that TMP, when administered as an inhaled aerosol targeting the lungs, can prevent the progression of $\mathrm{PH}$ in the MCT-induced $\mathrm{PH}$ rat model.

\section{Conclusions}

The physicochemical properties of TMP are reported comprehensively. The in vitro aerosol dispersion performance of spray dried TMP was tested using three different FDAapproved human dry powder inhaler devices. In vitro human cellular studies conducted on pulmonary cells from different regions of the human lung demonstrated biocompatibility and non-cytotoxicity of TMP. The in vivo healthy rat study demonstrated safety of inhaled TMP formulations as liquid aerosols and advanced dry powder aerosols. The in vivo diseased rat MCT model of PH study demonstrated that inhaled TMP aerosols, both as an inhaled liquid and dry powder, are efficacious in the attenuation of $\mathrm{PH}$.

Author Contributions: H.M.M. and J.X.-J.Y., Study Project Conception, Study Project Design, Experiments, Data Analysis, Interpretation, Manuscript Write-Up/Review/Editing; P.M., M.F.A., A.I.G., C.G., and H.T., Experiments, Data Analysis, Interpretation, Manuscript Write-Up/Review/Editing. All authors have read and agreed to the published version of the manuscript.

Funding: This work was partially supported by NIH NHLBI 1R01HL137282 (H.M.M.), NIH NIA R21AG054766 (H.M.M.), and a CONACyT Fellowship awarded to M.F.A. This material is based upon work supported by the National Science Foundation under Grant Number \#0619599 and Arizona Proposition 301: Technology and Research Initiative Fund (A.R.S.§15-1648).

Institutional Review Board Statement: The study was approved by University of Arizona Institutional Animal Care \& Use Committee.

Informed Consent Statement: Not applicable.

Data Availability Statement: The data presented in this study are available on request from the Corresponding Author.

Acknowledgments: SEM images and data were collected in the W.M. Keck Center for Nano-Scale Imaging in the Department of Chemistry and Biochemistry at the University of Arizona with funding from the W.M. Keck Foundation Grant. All Raman data was collected in the Imaging Cores Materials Imaging and Characterization Facility supported by the Office of Research, Discovery and Innovation at The University of Arizona. This material is based upon work supported by the National Science Foundation under Grant Number \#0619599 and Arizona Proposition 301: Technology and Research Initiative Fund (A.R.S.§15-1648). X-ray diffraction data were collected in the X-ray Diffraction Facility of the Department of Chemistry and Biochemistry, The University of Arizona. The authors thank Brooke Beam Masani (SEM), Sue Roberts (XRPD), Paul Wallace (Raman), and Chad Park (ATR-FTIR) at The University of Arizona for access to core facilities. The authors thank Nathan Cherrington for access to the microplate reader. The authors also thank Arlette Gladys Cordery for her assistance in the in vivo rodent study. This work was partially supported by NIH NHLBI 1R01HL137282 (HMM), NIH NIA R21AG054766 (HMM), and a CONACyT Fellowship awarded to M.F.A.

Conflicts of Interest: The authors declare no conflict of interest. 


\section{References}

1. Acosta, M.F.; Hayes, D.J.; Fineman, J.R.; Yuan, J.X.-J.; Black, S.M.; Mansour, H.M. Book Chapter 19: Therapeutics in Pulmonary Hypertension. In Inhalation Aerosols: Physical and Biological Basis for Therapy, 3rd ed.; Hickey, A.J., Mansour, H.M., Eds.; CRC Press/Taylor \& Francis: London, UK, 2019; pp. 313-322.

2. Stenmark, K.; Mecham, R. Cellular and molecular mechanisms of pulmonary vascular remodeling. Annu. Rev. Physiol. 1997, 59, 89-144. [CrossRef]

3. Farber, H.W.; Loscalzo, J. Pulmonary arterial hypertension. N. Engl. J. Med. 2004, 351, 1655-1665. [CrossRef]

4. Hill, N.S.; Preston, I.R.; Roberts, K.E. Inhaled Therapies for Pulmonary Hypertension. Respir. Care 2015, 60, 794-805. [CrossRef]

5. Kuhr, F.K.; Smith, K.A.; Song, M.Y.; Levitan, I.; Yuan, J.X. New mechanisms of pulmonary arterial hypertension: Role of Ca ${ }^{2+}$ signaling. Am. J. Physiol. Heart Circ. Physiol. 2012, 302, H1546-H1562. [CrossRef]

6. Gessler, T.; Seeger, W.; Schmehl, T. Inhaled prostanoids in the therapy of pulmonary hypertension. J. Aerosol Med. Pulm. Drug Deliv. 2008, 21, 1-12. [CrossRef] [PubMed]

7. Mansour, H.M. Inhaled Medical Aerosols by Nebulizer Delivery in Pulmonary Hypertension. Pulm. Circ. 2018, 8, 1-2. [CrossRef]

8. Kwan, C.Y. Plant-derived drugs acting on cellular ca2+ mobilization in vascular smooth muscle: Tetramethylpyrazine and tetrandrine. Stem Cells 1994, 12, 64-67. [CrossRef]

9. Chang, F.C.; Chen, K.J.; Lin, J.G.; Hong, C.Y.; Huang, Y.T. Effects of tetramethylpyrazine on portal hypertensive rats. J. Pharm. Pharmacol. 1998, 50, 881-884. [CrossRef] [PubMed]

10. Liu, S.; Cai, Y.; Evans, T.W.; McCormack, D.G.; Barer, G.R.; Barnes, P.J. Ligustrazine is a vasodilator of human pulmonary and bronchial arteries. Eur. J. Pharmacol. 1990, 191, 345-350. [CrossRef]

11. Cai, Y.; Bee, D.; Barer, G. Pulmonary vasodilator action of ligustrazine, active principle of a traditional Chinese remedy, in rats and ferrets. Proc. Chin. Acad. Med. Sci. Peking Union Med. Coll. 1988, 4, 147-152.

12. Oddoy, A.; Bee, D.; Emery, C.; Barer, G. Effects of ligustrazine on the pressure/flow relationship in isolated perfused rat lungs. Eur. Respir. J. 1991, 4, 1223-1227.

13. Li, S.Y.; Jia, Y.H.; Sun, W.G.; Tang, Y.; An, G.S.; Ni, J.H.; Jia, H.T. Stabilization of mitochondrial function by tetramethylpyrazine protects against kainate-induced oxidative lesions in the rat hippocampus. Free Radic. Biol. Med. 2010, 48, 597-608. [CrossRef]

14. Tan, F.; Fu, W.; Cheng, N.; Meng, D.I.; Gu, Y. Ligustrazine reduces blood-brain barrier permeability in a rat model of focal cerebral ischemia and reperfusion. Exp. Ther. Med. 2015, 9, 1757-1762. [CrossRef]

15. Wang, Y.; Zhu, H.; Tong, J.; Li, Z. Ligustrazine improves blood circulation by suppressing Platelet activation in a rat model of allergic asthma. Environ. Toxicol. Pharmacol. 2016, 45, 334-339. [CrossRef]

16. Wei, Y.; Liu, J.; Zhang, H.; Du, X.; Luo, Q.; Sun, J. Ligustrazine Attenuates Inflammation and the Associated Chemokines and Receptors in Ovalbumin-Induced Mouse Asthma Model. Environ. Toxicol. Pharmacol. 2016, 46, 55-61. [CrossRef]

17. Zhao, S.; Zhang, Y.; Chen, Q.; Dong, S.; Zhang, G.; Li, J. A Modified “Double-Hit” Induced Acute Lung Injury Model in Rats and Protective Effects of Tetramethylpyrazine on the Injury via Rho/ROCK Pathway. Int. J. Clin. Exp. Pathol. 2015, 8, 4581-4588. [PubMed]

18. Luo, Y.; Xiang, Q.; Wang, Q. Effect of Ligustrazine on Expression of RhoA mRNA, ROCK-II Protein in the Lung and Airway Inflammation of Allergic Asthma Model Mice. Chin. J. Pediatr. 2008, 46, 868-869.

19. Fan, X.; Wang, E.; He, J.; Zhang, L.; Zeng, X.; Gui, Y.; Sun, Q.; Song, Y.; Yuan, H. Ligustrazine Protects Homocysteine-Induced Apoptosis in Human Umbilical Vein Endothelial Cells by Modulating Mitochondrial Dysfunction. J. Cardiovasc. Transl. Res. 2019, 12, 591-599. [CrossRef] [PubMed]

20. Shi, J.; Wang, Y.; Luo, G. Ligustrazine Phosphate Ethosomes for Treatment of Alzheimer's Disease, In Vitro and in Animal Model Studies. AAPS Pharmscitech 2012, 13, 485-492. [CrossRef] [PubMed]

21. Yan, S.; Yue, Y.; Zeng, L.; Jiang, C.; Li, W.; Li, H.; Qian, Y. Ligustrazine nanoparticles nano spray's activation on Nrf2/ARE pathway in oxidative stress injury in rats with postoperative abdominal adhesion. Ann. Transl. Med. 2019, 7, 16. [CrossRef]

22. Liu, M.-W.; Su, M.-X.; Tang, D.--y.; Hao, L.; Xun, X.-H.; Huang, Y.-Q. Ligustrazin increases lung cell autophagy and ameliorates paraquat-induced pulmonary fibrosis by inhibiting PI3K/Akt/mTOR and hedgehog signalling via increasing miR-193a expression. BMC Pulm. Med. 2019, 19, 35. [CrossRef] [PubMed]

23. Gao, C.; Liu, Y.; Ma, L.; Zhang, X.; Wang, S. Effects of Ligustrazine on pulmonary damage in rats following scald injury. Burns 2012, 38, 743-750. [CrossRef]

24. Meenach, S.A.; Anderson, K.W.; Hilt, J.Z.; McGarry, R.C.; Mansour, H.M. High-Performing Dry Powder Inhalers of Paclitaxel DPPC/DPPG Lung Surfactant-Mimic Multifunctional Particles in Lung Cancer: Physicochemical Characterization, In Vitro Aerosol Dispersion, and Cellular Studies. AAPS Pharmscitech 2014, 15, 1574-1587. [CrossRef]

25. Olschewski, H.; Simonneau, G.; Galie, N.; Higenbottam, T.; Naeije, R.; Rubin, L.J.; Nikkho, S.; Speich, R.; Hoeper, M.M.; Behr, J.; et al. Inhaled iloprost for severe pulmonary hypertension. N. Engl. J. Med. 2002, 347, 322-329. [CrossRef] [PubMed]

26. Tissot, C.; Beghetti, M. Review of inhaled iloprost for the control of pulmonary artery hypertension in children. Vasc. Health Risk Manag. 2009, 5, 325-331. [PubMed]

27. Mansour, H.M.; Rhee, Y.-S.; Wu, X. Nanomedicine in pulmonary delivery. Int. J. Nanomed. 2009, 4, 299-319. [CrossRef]

28. Muralidharan, P.; Mallory, E.; Malapit, M.; Hayes, D.; Mansour, H.M. Inhalable PEGylated phospholipid nanocarriers and PEGylated therapeutics for respiratory delivery as aerosolized colloidal dispersions and dry powder inhalers. Pharmaceutics 2014, 6, 333-353. [CrossRef] 
29. Muralidharan, P.; Malapit, M.; Mallory, E.; Hayes, D.; Mansour, H.M. Inhalable nanoparticulate powders for respiratory delivery. Nanomed. Nanotechnol. Biol. Med. 2015, 11, 1189-1199. [CrossRef]

30. Xu, Z.; Mansour, H.M.; Hickey, A.J. Particle interactions in dry powder inhaler unit processes: A review. J. Adhes. Sci. Technol. 2011, 25, 451-482. [CrossRef]

31. Stocke, N.A.; Meenach, S.A.; Arnold, S.M.; Mansour, H.M.; Hilt, J.Z. Formulation and characterization of inhalable magnetic nanocomposite microparticles (MnMs) for targeted pulmonary delivery via spray drying. Int. J. Pharm. 2015, 479, 320-328. [CrossRef]

32. Mansour, H.M.; Rhee, Y.-S.; Park, C.-W.; De Luca, P.P. Lipid nanoparticulate drug delivery and nanomedicine. In Lipids in Nanotechnology; American Oil Chemists Society Press: Chicago, IL, USA, 2011; pp. 221-268.

33. Muralidharan, P.; Hayes, D.; Black, S.M.; Mansour, H.M. Microparticulate/nanoparticulate powders of a novel Nrf2 activator and an aerosol performance enhancer for pulmonary delivery targeting the lung Nrf2/Keap-1 pathway. Mol. Syst. Des. Eng. 2016, 1, 48-65. [CrossRef] [PubMed]

34. Li, X.; Mansour, H.M. Physicochemical characterization and water vapor sorption of organic solution advanced spray-dried inhalable trehalose microparticles and nanoparticles for targeted dry powder pulmonary inhalation delivery. AAPS Pharmscitech 2011, 12, 1420-1430. [CrossRef]

35. Meenach, S.A.; Vogt, F.G.; Anderson, K.W.; Hilt, J.Z.; McGarry, R.C.; Mansour, H.M. Design, physicochemical characterization, and optimization of organic solution advanced spray-dried inhalable dipalmitoylphosphatidylcholine (DPPC) and dipalmitoylphosphatidylethanolamine poly(ethylene glycol) (DPPE-PEG) microparticles and nanoparticles for targeted respiratory nanomedicine delivery as dry powder inhalation aerosols. Int. J. Nanomed. 2013, 8, 275-293. [CrossRef]

36. Wu, X.; Hayes, D., Jr.; Zwischenberger, J.B.; Kuhn, R.J.; Mansour, H.M. Design and physicochemical characterization of advanced spray-dried tacrolimus multifunctional particles for inhalation. Drug Des. Dev. Ther. 2013, 7, 59-72. [CrossRef]

37. Wu, X.; Zhang, W.; Hayes, D., Jr.; Mansour, H.M. Physicochemical characterization and aerosol dispersion performance of organic solution advanced spray-dried cyclosporine A multifunctional particles for dry powder inhalation aerosol delivery. Int. J. Nanomed. 2013, 8, 1269-1283. [CrossRef]

38. Li, X.; Vogt, F.G.; Hayes, D.; Mansour, H.M. Physicochemical characterization and aerosol dispersion performance of organic solution advanced spray-dried microparticulate/nanoparticulate antibiotic dry powders of tobramycin and azithromycin for pulmonary inhalation aerosol delivery. Eur. J. Pharm. Sci. 2014, 52, 191-205. [CrossRef]

39. Meenach, S.A.; Anderson, K.W.; Hilt, J.Z.; McGarry, R.C.; Mansour, H.M. Characterization and aerosol dispersion performance of advanced spray-dried chemotherapeutic PEGylated phospholipid particles for dry powder inhalation delivery in lung cancer. Eur. J. Pharm. Sci. 2013, 49, 699-711. [CrossRef] [PubMed]

40. Aerosols, Nasal Sprays, Metered-Dose Inhalers, and Dry Powder Inhalers Monograph. In USP 29-NF 24 The United States Pharmacopoeia and The National Formulary: The Official Compendia of Standards. 29/24; The United States Pharmacopeial Convention, Inc.: Rockville, MD, USA, 2006; pp. 2617-2636.

41. Acosta, M.F.; Muralidharan, P.; Meenach, S.A.; Hayes, D.; M-Black, S.; Mansour, H.M. In Vitro Pulmonary Cell Culture in Pharmaceutical Inhalation Aerosol Delivery: 2-D, 3-D, and In Situ Bioimpactor Models. Curr. Pharm. Des. 2016, 22, $2522-2531$. [CrossRef] [PubMed]

42. Meenach, S.A.; Tsoras, A.N.; McGarry, R.C.; Mansour, H.M.; Hilt, J.Z.; Anderson, K.W. Development of three-dimensional lung multicellular spheroids in air- and liquid-interface culture for the evaluation of anticancer therapeutics. Int. J. Oncol. 2016, 48, 1701-1709. [CrossRef] [PubMed]

43. Zhang, X.; Wei, J.; Ma, P.; Mu, H.; Wang, A.; Zhang, L.; Wu, Z.; Sun, K. Preparation and evaluation of a novel biodegradable long-acting intravitreal implant containing ligustrazine for the treatment of proliferative vitreoretinopathy. J. Pharm. Pharmacol. 2015, 67, 160-169. [CrossRef] [PubMed]

44. Li, X.; Vogt, F.; Hayes, D.J.; Mansour, H. Design, Characterization, and Aerosol Dispersion Performance Modeling of Advanced Spray-Dried Microparticulate/Nanoparticulate Mannitol Powders for Targeted Pulmonary Delivery as Dry Powder Inhalers. J. Aerosol Med. Pulm. Drug Deliv. 2014, 27, 81-93. [CrossRef]

45. Lee, H.J.; Kang, J.H.; Lee, H.G.; Kim, D.W.; Rhee, Y.S.; Kim, J.Y.; Park, E.S.; Park, C.W. Preparation and physicochemical characterization of spray-dried and jet-milled microparticles containing bosentan hydrate for dry powder inhalation aerosols. Drug Des. Dev. Ther. 2016, 10, 4017-4030. [CrossRef] [PubMed]

46. Martinelli, F.; Balducci, A.G.; Kumar, A.; Sonvico, F.; Forbes, B.; Bettini, R.; Buttini, F. Engineered sodium hyaluronate respirable dry powders for pulmonary drug delivery. Int. J. Pharm. 2017, 517, 286-295. [CrossRef]

47. Hickey, A.J.; Mansour, H.M. Formulation Challenges of Powders for the Delivery of Small Molecular Weight Molecules as Aerosols. Drugs Pharm. Sci. 2003, 126, 835-848.

48. Park, C.W.; Li, X.; Vogt, F.G.; Hayes, D., Jr.; Zwischenberger, J.B.; Park, E.S.; Mansour, H.M. Advanced spray-dried design, physicochemical characterization, and aerosol dispersion performance of vancomycin and clarithromycin multifunctional controlled release particles for targeted respiratory delivery as dry powder inhalation aerosols. Int. J. Pharm. 2013, 455, 374-392. [CrossRef]

49. Longest, P.W.; Son, Y.J.; Holbrook, L.; Hindle, M. Aerodynamic factors responsible for the deaggregation of carrier-free drug powders to form micrometer and submicrometer aerosols. Pharm. Res. 2013, 30, 1608-1627. [CrossRef] 
50. Mansour, H.M.; Xu, Z.; Hickey, A.J. Dry powder aerosols generated by standardized entrainment tubes from alternative sugar blends: 3. Trehalose dihydrate and D-mannitol carriers. J. Pharm. Sci. 2010, 99, 3430-3441. [CrossRef] [PubMed] 
51. Xu, Z.; Mansour, H.M.; Mulder, T.; McLean, R.; Langridge, J.; Hickey, A.J. Comparative Dispersion Study of Dry Powder Aerosols of Albuterol Sulfate/Lactose Monohydrate and Cromolyn Sodium/Lactose Monohydrate Delivered by Standardized Entrainment Tubes. In Respiratory Drug Delivery XI; Dalby, R.N., Bryon, P.R., Suman, J.D., Peart, J., Farr, S.J., Eds.; Davis Healthcare International Publishing, LLC: Scotsdale, AZ, USA, 2008; Volume 3, pp. 897-900.

52. Xu, Z.; Mansour, H.M.; Mulder, T.; McLean, R.; Langridge, J.; Hickey, A.J. Dry powder aerosols generated by standardized entrainment tubes from drug blends with lactose monohydrate: 2. Ipratropium bromide monohydrate and fluticasone propionate. J. Pharm. Sci. 2010, 99, 3415-3429. [CrossRef]

53. Xu, Z.; Mansour, H.M.; Mulder, T.; McLean, R.; Langridge, J.; Hickey, A.J. Dry powder aerosols generated by standardized entrainment tubes from drug blends with lactose monohydrate: 1. albuterol sulfate and disodium cromoglycate. J. Pharm. Sci. 2010, 99, 3398-3414. [CrossRef]

54. Xu, Z.; Mansour, H.M.; Mulder, T.; McLean, R.; Langridge, J.; Hickey, A.J. Heterogeneous particle deaggregation and its implication for therapeutic aerosol performance. J. Pharm. Sci. 2010, 99, 3442-3461. [CrossRef] [PubMed]

55. Muralidharan, P.; Hayes, D., Jr.; Mansour, H.M. Dry powder inhalers in COPD, lung inflammation and pulmonary infections. Expert Opin. Drug Deliv. 2015, 12, 947-962. [CrossRef] [PubMed] 